\title{
Global and regional estimates of warm cloud droplet number concentration based on 13 years of AQUA-MODIS observations
}

\author{
Ralf Bennartz $^{1,2}$ and John Rausch ${ }^{1}$ \\ ${ }^{1}$ Earth and Environmental Science Department, Vanderbilt University, Nashville, TN 37240, USA \\ ${ }^{2}$ Space Science and Engineering Center, University of Wisconsin, Madison, WI 53706, USA \\ Correspondence to: Ralf Bennartz (ralf.bennartz@ vanderbilt.edu)
}

Received: 17 December 2016 - Discussion started: 10 January 2017

Revised: 11 July 2017 - Accepted: 17 July 2017 - Published: 22 August 2017

\begin{abstract}
We present and evaluate a climatology of cloud droplet number concentration (CDNC) based on 13 years of Aqua-MODIS observations. The climatology provides monthly mean $1 \times 1^{\circ} \mathrm{CDNC}$ values plus associated uncertainties over the global ice-free oceans. All values are incloud values, i.e. the reported CDNC value will be valid for the cloudy part of the grid box. Here, we provide an overview of how the climatology was generated and assess and quantify potential systematic error sources including effects of broken clouds, and remaining artefacts caused by the retrieval process or related to observation geometry. Retrievals and evaluations were performed at the scale of initial MODIS observations (in contrast to some earlier climatologies, which were created based on already gridded data). This allowed us to implement additional screening criteria, so that observations inconsistent with key assumptions made in the CDNC retrieval could be rejected. Application of these additional screening criteria led to significant changes in the annual cycle of CDNC in terms of both its phase and magnitude. After an optimal screening was established a final CDNC climatology was generated. Resulting CDNC uncertainties are reported as monthly-mean standard deviations of CDNC over each $1 \times 1^{\circ}$ grid box. These uncertainties are of the order of $30 \%$ in the stratocumulus regions and 60 to $80 \%$ elsewhere.
\end{abstract}

\section{Introduction}

Presently one of the largest sources of uncertainty in predicting future climate is the degree to which clouds will alter the Earth's radiative balance (Stocker et al., 2013). In particular, stratiform boundary layer clouds play an important role in modulating earth albedo and are "at the heart of tropical feedback uncertainties in climate models" (Bony and Dufresne, 2005). Aerosol-cloud interactions contribute to these uncertainties, e.g. through the first indirect aerosol effect (Twomey, 1974), in which an aerosol-perturbed cloud reflects solar radiation more efficiently than an unperturbed cloud under otherwise identical conditions.

Satellite observations play a critical role in understanding current-day variability of clouds, in validating and constraining climate models, and in furthering our understanding of cloud processes. Based on earlier work (Brenguier et al., 2000; Schuller et al., 2005, 2003; Han et al., 1998), Bennartz (2007) published an initial version of a cloud droplet number concentration (CDNC) climatology for liquid boundary layer clouds using cloud parameters derived from NASA's Aqua Moderate Resolution Imaging SpectroRadiometer (MODIS). Similar efforts were reported by Quaas et al. (2006). Revised and extended versions of this climatology have been used for climate model validation and evaluation (Storelvmo et al., 2009; Hoose et al., 2008, 2009; Makkonen et al., 2009; Y. Zhang et al., 2012; He et al., 2015; Wang et al., 2015; Ban-Weiss et al., 2014). A variety of observational case studies and process studies were also published using similar approaches for deriving CDNC (Boers et al., 2006; George and Wood, 2010; Painemal and Zuidema, 2010; Rausch et al., 2010; Bennartz et al., 2011). Various authors have addressed shortcomings and issues related to CDNC climatologies (Merk et al., 2016; Grosvenor and Wood, 2014) as well as issues related to the cloud retrievals underlying the CDNC climatologies (Zhang and Platnick, 2011; Nakajima et al., 2010; Maddux et al., 2010; Horvath et al., 2014). Painemal and Zuidema (2011) 
validate MODIS-derived CDNC against in situ observations taken in the South Pacific during VOCALS-Rex (Wood et al., 2011). Wood et al. (2012) point out important other factors, for example precipitation generation, that hamper the interpretation of CDNC results in correlative observational studies in the context of the first indirect aerosol effect. Several studies also propose different and potentially more elaborate approaches for deriving CDNC. For example, Rosenfeld et al. (2012) propose a spatially highly resolving satellite mission dedicated to the retrieval of cloud condensation nuclei for convective clouds and also point to limitations of the CDNC retrieval approach pursued here when applied to convective clouds. Zeng et al. (2014) propose a combination of Cloud-Aerosol Lidar with Orthogonal Polarization (CALiOP) observations with MODIS observations to retrieve CDNC.

In light of these developments, the objective of the present paper is 3 -fold. Firstly, we wish to update older versions of the CDNC climatology by Bennartz (2007) accounting for the 13 full years of Aqua-MODIS observations available by now, taking advantage of the revised and improved NASA MODIS Collection 6 cloud retrievals as outlined in Platnick et al. (2015), with better traceability via DOI assignment. Secondly, we wish to provide readers and users of the climatology with a comprehensive overview of issues and limitations of the climatology. Thirdly, we wish to quantitatively assess possible systematic error sources, quantify uncertainties, and provide validation of the climatology.

Systematic errors in the CDNC climatology stem largely from assumptions made in the retrieval process and in the cloud model that underlies the CDNC retrievals. In particular three assumptions are critical throughout the retrieval process.

1. The cloud is assumed to be horizontally homogeneous at the scale of an individual MODIS pixel of about $1 \times 1 \mathrm{~km}$. This is an assumption frequently made in various cloud retrievals, not only CDNC retrievals. It potentially leads to systematic errors for situations where the observed scene deviates from horizontal homogeneity.

2. Cloud liquid water content (LWC) is assumed to increase linearly from cloud base to cloud top. The rate of increase in LWC with height (in $\mathrm{kg} \mathrm{m}^{-4}$ ) is often called the "condensation rate", similar to the use of the term "lapse rate" for the change in temperature with height. The assumption of linearity has been a matter of some confusion in the context of CDNC retrievals. We point out that it is not necessary to hold the condensation rate constant at its maximum adiabatic value, which is a weak function of temperature and pressure. A strict linear increase in LWC is also not necessary as long as reasonable assumptions about the vertical LWC profile are made. For example, Boers et al. (2006) re- lax the strict linear assumption near cloud top to better account for cloud top entrainment.

3. CDNC is typically assumed constant throughout the cloud's vertical extent. This assumption can also be relaxed somewhat as long as a clear dependency of CDNC on height above cloud base exists.

In the past, we have labelled these three assumptions collectively the "adiabatic cloud model". This labelling appeared justified because the above-described assumptions are inspired by an idealized air parcel rising under moist adiabatic conditions. However, here we refrain from using the term "adiabatic cloud model" as it has led to misunderstandings mostly revolving around the usage of the word "adiabatic". Indeed, the cloud model described above is not strictly adiabatic as it allows for modification and deviations from strict adiabaticity in terms of the profile of both LWC and CDNC. A term that probably better, albeit less attractively, would describe the intent of the above assumptions would be the "Idealized Stratiform Boundary Layer Cloud" (ISBLC) model, which we will use throughout this paper. In fact, most authors use sub-adiabatic profiles and condensation rates around $80 \%$ of their maximum value are often found in experimental studies (Wood, 2012). A recent study by Merk et al. (2016) finds LWC at about $75 \%$ of its adiabatic value in updrafts and about $60 \%$ of its maximum adiabatic value in downdrafts.

While the ISBLC captures important aspects of actual stratiform boundary layer clouds, none of its assumptions will ever be fully valid for any observed cloud. The true three-dimensional variability of clouds poses significant challenges to any remote sensing algorithm and recent studies have made progress toward understanding and possibly correcting the impact of this variability on cloud remote sensing (Z. Zhang et al., 2012, 2016, and references therein). Furthermore, the cloud microphysical interpretation of retrieved CDNC is also not straightforward. Entrainment mixing processes, precipitation formation, and additional activation above cloud base can lead to differences between the number of cloud droplets activated at cloud base and the number of cloud droplets observed. Studies interested in activation of cloud droplets at cloud base would need to take these differences into account. We will elaborate more on issues related to three-dimensional cloud structure as well as cloud microphysical assumptions in Sect. 3.

The remainder of this paper is structured as follows. In Sect. 2 we briefly describe the datasets as well as the principal methods used here to derive CDNC from satellite observations. Section 3 summarizes issues related to the use of the ISBLC as well as other assumptions made in the retrieval process, thereby providing interpretational context for the use of satellite-derived CDNC retrievals as well as guidance on the expected magnitude and relative importance of uncertainties introduced by the various assumptions. In Sect. 4 we address actual uncertainties and possible biases 
in CDNC retrievals. Potential biases are for example caused by remaining artefacts in the underlying MODIS retrievals caused by unresolved dependencies on observation geometry or underlying assumptions on the width of the droplet spectrum. In addition, in Sect. 4 we also validate our CDNC retrievals against in situ observations of CDNC taken during the VOCALS-Rex campaign and summarized by Painemal and Zuidema (2011). In Sect. 5 we evaluate the 13-year climatology of MODIS observations. In our analysis we put particular emphasis on the phase and amplitude of the observed annual cycle of CDNC over various regions of the globe. We further identify areas where trends in CDNC are observed. In Sect. 6 we provide concluding remarks and discussion of remaining issues that could help improve future satellite-based CDNC estimates.

\section{Datasets and methods}

\subsection{MODIS Collection 6 cloud parameters}

Observational data are from NASA's MODIS Collection 6 (C6) Level-2 Cloud Product (Platnick et al., 2015, 2017). The term "Level-2" refers to individual MODIS cloud retrievals at a resolution of $1 \times 1 \mathrm{~km}$ at nadir. The Level-2 Cloud Product provides retrievals of cloud optical thickness, cloud top temperature, and three droplet effective radii retrievals using radiances observed at 1.6, 2.1, and $3.7 \mu \mathrm{m}$. These cloud parameter retrievals form the basis of our CDNC retrievals. Relative to the earlier MODIS Collection 5, there are several improvements in retrievals of parameters necessary to determine CDNC. These improvements include a better coregistration of the visible and near-infrared focal planes of the Aqua-MODIS instrument as well as significant improvements in the forward radiative transfer models used in the retrieval framework (Platnick et al., 2015). The impact of these changes on CDNC retrievals and gridded climatologies is assessed in detail in Rausch et al. (2017). For the current study, Level-2 cloud retrievals are from Aqua-MODIS spanning the years 2003 through 2015. Additionally, for some comparisons with in situ observations, selected Terra-MODIS granules were used also.

\subsection{Derivation of CDNC}

Under the ISBLC assumption, closed formulas can be derived that relate between two different pairs of cloud physical variables. The first pair of variables are cloud optical depth and effective radius at cloud top, and the second pair of variables are CDNC and cloud geometrical thickness (Brenguier et al., 2000). Following the notation of Bennartz (2007), these relations are

$W=\frac{5}{9} \rho_{1} \tau r_{\mathrm{e}, \mathrm{top}}=\frac{1}{2} c_{\mathrm{W}} H^{2}$ where $W$ is the liquid water path, $\rho_{1}$ the density of liquid water, $\tau$ the optical depth, $r_{\mathrm{e} \text {,top }}$ the effective radius at the top of the idealized ISBLC, $c_{\mathrm{W}}$ the condensation rate, and $H$ the ISBLC's geometrical thickness. The second relation provides an estimate for CDNC:

$N=\frac{\tau^{3}}{k}[2 W]^{\frac{-5}{2}}\left[\frac{3}{5} \pi Q\right]^{-3}\left[\frac{3}{4 \pi \rho_{1}}\right]^{-2} c_{\mathrm{W}}^{\frac{1}{2}}$,

where $N$ represents CDNC, $k$ is a factor related to the dispersion of the assumed cloud droplet size distribution, and $Q$ is the scattering efficiency of the cloud droplets. The variable $k$ exhibits some variability (Brenguier et al., 2011; Martin et al., 1994) but is set constant at a value of $k=0.8$ here. A realistic uncertainty estimate for $k$ between different studies is about $20 \%$. Similarly, $Q$ is set to its geometric optics limit value of $Q=2$. Bennartz (2007) shows that uncertainties in the representation of $Q$ and $k$ are only a minor contributor to the total uncertainty in $N$ and $H$. The condensation rate $c_{\mathrm{w}}$ is calculated as $80 \%$ of its maximum adiabatic value for the MODIS-derived cloud top temperature (CTT). In summary, our particular implementation of the ISBLC for the climatology presented here is CDNC constant vertically, $k=0.8$, $Q=2$, and $c_{\mathrm{w}}=0.8 \times f(\mathrm{CTT})$, where $f(\mathrm{CTT})$ is the full adiabatic condensation rate as a function of cloud top temperature (at a pressure assumed fixed at $850 \mathrm{hPa}$ ).

The above equations allow for a conversion between ( $\tau$, $\left.r_{\mathrm{e}, \text { top }}\right)$ and $(N, H)$, thereby enabling the use of NASA's retrieved effective radius and optical depth for calculating CDNC without the need for dedicated retrieval algorithms that would have to be built on Level-1 reflectances. An important assumption made in this conversion between $(\tau$, $\left.r_{\mathrm{e}, \text { top }}\right)$ and $(N, H)$ is that the retrieved effective radius is valid at the top of the ISBLC, as indicated by the subscript "top" in the above equations. However, satellite-derived effective radii are typically valid at some penetration below cloud top that depends on observation wavelength and geometry. Thus, if the satellite-derived effective radius is used directly in the above conversion, one assumes that $r_{\mathrm{e}, \text { top }}=r_{\mathrm{e}}$,retrieved. Throughout this paper we employ this assumption and use the effective radius retrieved at $3.7 \mu \mathrm{m}$ to calculate CDNC. The implications and limitations of this assumption are discussed further in Sect. 3.

\subsection{Gridded climatology}

The individual CDNC retrievals discussed above were used to calculate global fields of monthly averages of CDNC on a regular $1^{\circ} \times 1^{\circ}$ latitude-longitude grid for the 13 years 2003-2015. First, daily averages were calculated as the arithmetic mean of all Level-2 MODIS-retrieved CDNC values within each $1^{\circ} \times 1^{\circ}$ grid box within 1 day. In order to provide a valid daily $1 \times 1^{\circ}$ average, at least 10 valid Level- 2 retrievals had to be within that grid box. Screening criteria performed on individual pixels are outlined further below. If, for a given month and grid box, more than 10 days had valid 
daily values, the arithmetic mean of those was assigned to be the monthly mean value. The so-derived monthly mean fields, along with uncertainty estimates, are part of the published dataset.

Uncertainty estimates were generated as follows: in addition to the daily mean value of CDNC for each $1^{\circ} \times 1^{\circ}$ grid box, the variance of Level-2 CDNC observations within this grid box was also calculated. The monthly uncertainty for this grid box was then calculated as the square root of the mean of the daily variances over the course of each month, thereby assuming uncertainties between days to be uncorrelated. This approach of creating monthly uncertainties is similar to the approach used in NASA's Level-3 gridded MODIS cloud product (Hubanks et al., 2016). The difference between our approach and that of NASA is that we calculate the underlying daily grid-box-level uncertainties from spatial standard deviations of retrieved CDNC, whereas NASA uses a posteriori retrieval errors as the basis for their daily grid-boxlevel uncertainties. We address the difference between these two choices with respect to CDNC in Sect. 4.

In order to ensure that only valid cloud observations were accumulated, a series of screening criteria were used on each Level-2 data point. The impact of different screening choices is discussed in Sect. 4. Here we list the final set of screening choices made in the climatology.

1. Both the infrared-derived and the visible/near-infraredderived cloud phases had to indicate a liquid water cloud.

2. The retrieved cloud top temperature had to be between 268 and $300 \mathrm{~K}$.

3. The cloud mask had to indicate the observation to be cloudy, but not over ice or land.

4. Clear-sky restoral and pixels identified in the MODIS Level-2 cloud product as partly cloudy pixels were not included.

5. All three effective radii retrieved at 1.6, 2.1, and $3.7 \mu \mathrm{m}$, respectively, as well as the three corresponding retrieved optical thicknesses, had to be valid.

6. Observations were only considered if the three MODISretrieved effective radii stacked up as $r_{\mathrm{e}, 3.7}>r_{\mathrm{e}, 2.1}>$ $r_{\mathrm{e}, 1.6}$. Observations violating this criterion will also violate the key assumption of a vertically increasing LWC in the ISBLC. More details on the motivation of this screening criterion are provided subsequently in Sect. 3 .

\section{Assumptions and limitations of the ISBLC}

NASA's "MODIS effective radius and optical thickness retrievals build on the use of Nakajima-King Diagrams" (Nakajima and King, 1990) similar to the red mesh shown in Fig. 1.
The retrieval algorithms effectively map between the observed reflectances, on the $x$ - and $y$-axis, and the retrieved $\left(\tau, r_{\mathrm{e}, \text { retrieved }}\right)$ parameters shown in the red mesh. Details on the actual retrievals used in MODIS C6 can be found in Platnick et al. (2015). Note that NASA's operational retrievals, as most other retrievals, are performed using a cloud model in which effective radius and liquid water content are constant vertically, thereby replacing assumptions 2 and 3 of the ISBLC while maintaining its assumption 1. This cloud model is sometimes called the Vertically Homogeneous Cloud (VHC) model. The ISBLC-based relation between $(N, H)$ and the observed reflectances is also depicted in Fig. 1 (blue mesh).

Subsequently, we discuss several issues related to the retrieval of cloud optical properties in general and CDNC in particular. All radiative transfer simulations underlying the discussions in this section were performed using the Spherical Harmonics Discrete Ordinate Method (SHDOM) model (Evans, 1998). Spectral optical properties for all aerosols were taken from the Optical Properties of Aerosols and Clouds (OPAC) database (Hess et al., 1998). Simulations were performed for idealized situations over a black surface, nadir observations, and a solar zenith angle of $56^{\circ}$. The resulting scattering angle of $124^{\circ}$ samples the phase function in a relatively smooth region outside of the backscatter or rainbow peaks. Retrievals on simulated data were performed using Levenberg-Marquardt optimization. Scattering angle is defined as the angle between the Sun, the point of observation, and the satellite. A value of $180^{\circ}$ defines the backscatter direction. Clouds were assumed to be at $288 \mathrm{~K}$. CDNC was varied within the ISBLC between 10 and $2000 \mathrm{~cm}^{-3}$ and geometrical thickness $H$ was varied between 20 and $2000 \mathrm{~m}$.

\subsection{Penetration depth}

Figure 2 shows the penetration depth of radiation into ISBLCs as relevant for effective radius retrievals. Firstly, a series of reflectances for ISLBCs with different CDNCs and geometrical thicknesses were calculated using SHDOM as described above. The so-derived reflectances were used as "observations". Secondly, these "observations" were input to retrieval algorithms using the VHC model (red meshes in Fig. 1). We keep the quotation marks around "observations" here to indicate that this is a simulation experiment. The simulated retrieval process is an analogue to the actual MODIS effective radius retrieval where VHC retrievals are applied to stratiform boundary layer clouds that are typically vertically stratified. The so-retrieved effective radius is then compared to the effective radius profile of the ISBLCs that underlie the "observations". The penetration depth is then defined as the height below cloud top, where the retrieved effective radius equals the actual effective radius of the underlying ISBLC. The definition of penetration depth used here cannot be considered directly as the radiative penetration depth at a given wavelength because it uses two-channel effective radius retrievals to determine where vertically the retrieved effective 

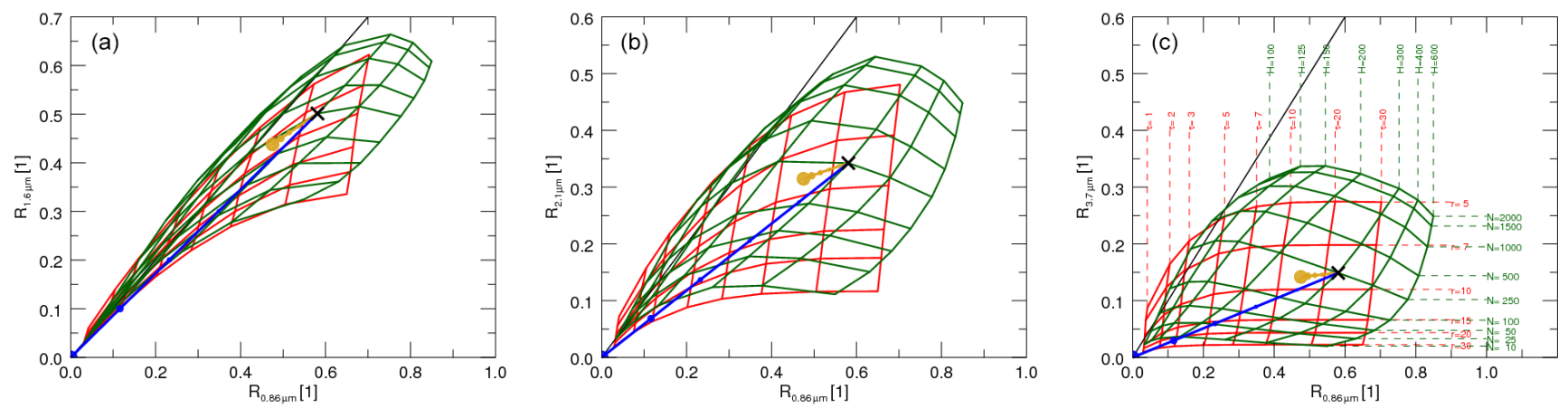

Figure 1. Nakajima-King plots showing idealized relations between satellite-observed reflectances and retrieved cloud variables over a black surface for all three MODIS bands used for retrievals. The $x$-axis shows the reflectances at $0.86 \mu$, the $y$-axis the reflectance at $1.6,2.1$, and $3.7 \mu \mathrm{m}$, respectively. The red mesh shows the dependency of retrieved optical depth (" $\tau$ ", dimensionless, given in panel c) and retrieved effective radius (" $r$ ", in $\mu \mathrm{m}$ ) on reflectance. The green mesh shows the dependency of retrieved CDNC (“ $N$ ", in $\mathrm{cm}^{-3}$ ) and cloud geometrical thickness (" $H$ ", in metres) on the reflectance. The thin black line is the one-to-one line for reference. The thick blue and golden lines indicate the impact of partly cloudy scenes (blue) and absorbing aerosol above the clouds (golden). More details are provided in the text.
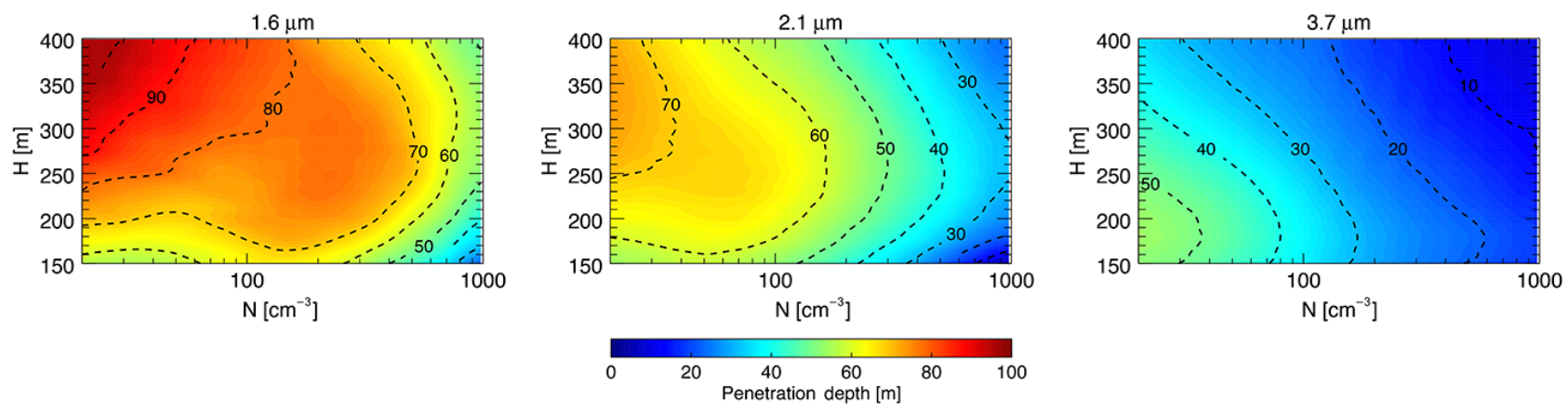

Figure 2. Average penetration depth relevant for effective radius retrievals of CDNC in the ISBLC. For the purpose of this study, we define the penetration depths as the vertical distance below cloud top at which the retrieved effective radius equals the effective radius predicted by the ISBLC.

radius is representative. For a full discussion of the radiative penetration depth, we refer the reader to Platnick (2000), who also discusses in detail the difference between our definition and the radiative penetration depth as well as angular dependencies.

From Fig. 2 one can identify that at $1.6 \mu \mathrm{m}$ the penetration depth is about 2 to 3 times higher than that at $3.7 \mu \mathrm{m}$. The results are in good general agreement with the results shown in Platnick (2000). See e.g. Table 4 therein. The resulting retrieved effective radii at the three wavelengths are typically within about $1-2 \mu \mathrm{m}$ of each other, with the $3.7 \mu \mathrm{m}$ effective radius being the largest. Actual clouds of course deviate often substantially from ISBLCs. Some issues related to cloud inhomogeneities are discussed next.

\subsection{Cloud inhomogeneities}

The liquid water content profile often does not increase linearly with height above cloud base and CDNC and effective radius might be reduced near cloud top. In particular inhomogeneous mixing processes reduce CDNC and are ob- served frequently in boundary layer clouds (Burnet and Brenguier, 2007). Furthermore, horizontal inhomogeneities have a critical impact on cloud optical property retrievals. Such artefacts in cloud retrievals associated with inhomogeneous sub-pixel cloud cover have been discussed in detail for example in Zhang and Platnick (2011) and Horvath and Gentemann (2007) among others. Drizzle processes also significantly alter cloud horizontal and vertical structure, and droplet number concentration (Wood, 2012, 2005). Drizzle might also contribute directly to the observed reflectances, thereby increasing the retrieved effective radius at $1.6 \mu \mathrm{m}$ (Suzuki et al., 2011). Typically, most of these issues affect the effective radius at 1.6 and $2.1 \mu \mathrm{m}$ more strongly than the effective radius at $3.7 \mu \mathrm{m}$ (Z. Zhang et al., 2012). However, at high solar zenith angles Grosvenor and Wood (2014) demonstrated that resolved (as opposed to sub-pixel) threedimensional radiative effects are likely to cause the effective radius to be biased high, with larger biases expected for the $3.7 \mu \mathrm{m}$ retrieval compared to the $1.6 \mu \mathrm{m}$ one. 

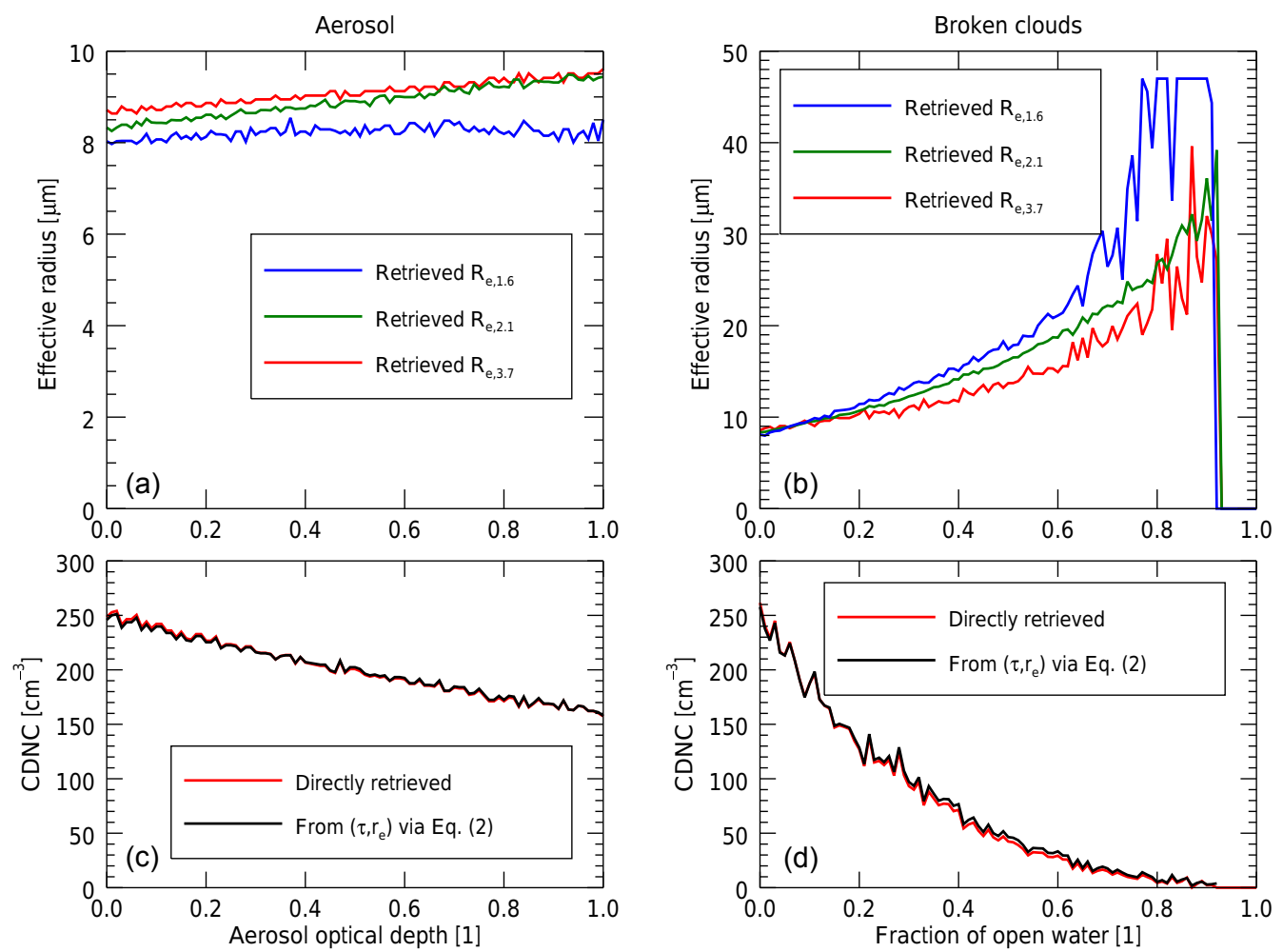

Figure 3. Simulated retrieval for effective radius (a, b) and CDNC (c, d) for the aerosol-affected (a, c) and partly cloudy reflectances (b, d), respectively, shown in Fig. 1. CDNC retrievals tagged "directly retrieved" are performed using the green meshes in Fig. 1, rightmost panel, whereas CDNC retrievals marked "from Eq. (2)" are derived by first using the $3.7 \mu \mathrm{m}$ optical depth and effective radius retrieval and subsequently converting it to CDNC using Eq. (2). This latter approach is similar to the actual way we retrieve CDNC from MODIS cloud optical properties. The "Fraction of open water" refers to the fraction of an inhomogeneous Level-2 MODIS pixel that is not covered by cloud.

The blue line depicted in Fig. 1 highlights the issue. Even without accounting for the three-dimensional radiative transfer, partly cloudy scenes will exhibit positively biased effective radii. The blue cross in Fig. 1 corresponds to an ISBLC with $N=500 \mathrm{~cm}^{-3}$ and $H=175 \mathrm{~m}$. The blue line gives the resulting observed reflectance, if this cloud covers between 0 and $100 \%$ of the sensor's field of view. For all three wavelengths the blue line cuts through the retrieval grid toward larger effective radii and smaller CDNC. Figure 3 (right panels) shows the impact on retrieved effective radii as one moves from completely cloudy to nearly cloud-free. For subpixel fractions of open water above $10 \%$ the retrieved effective radius at $1.6 \mu \mathrm{m}$ starts to exceed 2.1 and $3.7 \mu \mathrm{m}$, but all three effective radii increase significantly as the pixel becomes less cloud-filled. Z. Zhang et al. (2012) and Hayes et al. (2010) discuss this effect in more detail, which is also present in case of sub-scale inhomogeneities of fully cloudcovered observations (i.e. if cloud thickness and liquid water path vary within the field of view). Shading and side illumination of broken clouds as well as true three-dimensional radiative transfer effects modify this picture somewhat, but at the same time the inherent averaging performed over a
$1 \times 1 \mathrm{~km}^{2}$ MODIS field of view averages out some of these higher-order effects (Z. Zhang et al., 2012). Because of the strong impact of sub-scale inhomogeneity we have limited the climatology to cases where $r_{\mathrm{e}, 3.7}>r_{\mathrm{e}, 2.1}>r_{\mathrm{e}, 1.6}$, so that in the example shown in Fig. 3 (right panels) the largest part of the retrievals would be (correctly) rejected. We discuss the impact of this criterion on the actual climatology in Sect. 4.

\subsection{Aerosol above clouds}

Another important topic related to effective radius and CDNC retrievals is the impact of aerosol above clouds. This has received a significant amount of attention in the literature as especially off South Africa biomass burning aerosols, consisting of black carbon (soot), organic compounds, ammonium, nitrate, and sulfate, are often vertically displaced above the stratocumulus clouds by several kilometres (Wilcox et al., 2009; Painemal et al., 2014; Wilcox, 2012; Haywood et al., 2004). We illustrate the effect of aerosol layers on retrievals in Fig. 1 (see the golden curve with a large dot at the end). We start from the black cross in Fig. 1, which corresponds to an ISBLC with $N=500 \mathrm{~cm}^{-3}$ and $H=175 \mathrm{~m}$. From there we increase aerosol load above the cloud from zero to an 
optical depth at $550 \mathrm{~nm}$ of one toward the golden dot. The aerosol type we choose is "continental polluted" from the OPAC database (Hess et al., 1998), which has roughly similar optical properties to the aged biomass burning aerosol reported in Haywood et al. (2003). The corresponding retrievals are shown in Fig. 3 (left panels). As aerosol optical depth increases, the retrieved effective radius increases and the retrieved optical depth decreases. This results in a decrease in CDNC with increasing aerosol optical depth. The impact of aerosol above clouds depends highly on its single scattering albedo. The more absorbing the aerosol is, the stronger the effect. Note that, unlike for broken clouds, the retrieved effective radius at $3.7 \mu \mathrm{m}$ remains larger than the 2.1 and $1.6 \mu \mathrm{m}$ effective radii. Therefore, the criterion $r_{\mathrm{e}, 3.7}>r_{\mathrm{e}, 2.1}>r_{\mathrm{e}, 1.6}$ does not help reject potentially aerosolaffected observations. Note further that the effect of aerosol on effective radius can also lead to a decrease in effective radius with increasing aerosol optical depth, depending on observation geometry and where exactly in the Nakajima-King diagrams the observation lies.

\section{Sensitivity studies}

In this section we study the sensitivity of the climatology to choices made in the underlying retrievals as well as data screening choices, such as the aforementioned criterion $r_{\mathrm{e}, 3.7}>r_{\mathrm{e}, 2.1}>r_{\mathrm{e}, 1.6}$. We further investigate dependencies of the retrieved CDNC and effective radii on scattering angle and sunglint angle and provide a discussion of uncertainties derived alongside the CDNC climatology. The sunglint angle is defined as the angle between the satellite, the point of observation, and the direct specular reflection of sunlight off the ocean surface. Lastly, we evaluate the climatology against the limited set of in situ CDNC observations that were readily available to us. Except for the comparisons to in situ observations all sensitivity studies were done by re-deriving and stratifying 1 full year (2008) of MODIS data by different quantities, such as the scan angle or position within the scan.

\subsection{Impact of observation geometry}

Various studies have already shown that scan-dependent biases existed in the older Collection 5 version of MODIS. For example, Maddux et al. (2010) find significantly larger effective radius retrievals along with lower optical depth retrievals near the scan edge than in the centre of the scan. Grosvenor and Wood (2014) address the dependency of cloud microphysical retrievals on solar zenith angle, demonstrating possible increases in CDNC by 40 to $70 \%$ at solar zenith angles higher than about $70^{\circ}$. Issues related to the observation geometry can in principle stem from two different sources. Firstly, as the solar or observation zenith angle increases, the potential effects of side illumination and shading become more pronounced and, for an increasing observation zenith angle, the field of view also gets larger. Secondly, assumptions and constraints of the retrieval itself might cause artefacts. For example, the choices made on whether to include sunglint-affected areas might cause differences, or the discretization of the retrieval to particular combinations of observation geometries can cause artefacts in the retrieval. When creating climatologies based on a large number of observations, some of these artefacts might average out, whereas others might cause systematic biases also in the climatologies. Subsequently, we first stratify results by various quantities to identify and discuss potential artefacts. Then, we study the impact of these artefacts on the climatology.

Figure 4 shows the dependency of effective radius, optical depth, and CDNC retrievals on both scattering angle and sunglint angle. Results indicate averages over all valid retrievals for the year 2008 applying the screening criteria corresponding to "Stratified" and "Non-stratified" (see Table 1 for details on screening criteria). One can identify a variety of different artefacts in the dataset. In all cases the "Stratified" results (blue) show the artefacts more strongly than the "Nonstratified" cases. We suspect this is caused by the generally larger variability seen in the "Non-stratified" cases caused by the issues discussed in Sect. 3 (e.g. horizontal inhomogeneity). Observations affected by e.g. inhomogeneity are at least partly screened out in the "Stratified" dataset, which therefore shows additional artefacts more strongly. From Fig. 4 the following issues can be identified.

- Near the rainbow peak (scattering angle around $145^{\circ}$ ) and the backscatter peak (scattering angle $180^{\circ}$ ) the average retrieved effective radii vary in a manner that roughly resembles the phase function of typical droplet spectra. For these two regions the optical depth is comparably flat with much less variation than the effective radius. We speculate that these artefacts could be caused either by the treatment of single scattering in the MODIS C6 retrievals or by deviations between the spectral widths of the droplet spectra used in the retrievals and the real-world droplet spectra. The "hybrid discretization scheme" used in MODIS C6 retrieval is outlined in Platnick et al. (2015); see Table 2.92 therein. While the single scattering contribution is calculated exactly at the angles provided in the LUT, larger interpolation errors appear to occur in the rainbow and backscattering region (Platnick et al., 2015; see Fig. 2.9-3, lower right panel), potentially consistent with the features found here. The second possible source of deviations, potential differences between observed and simulated droplet spectral widths, could potentially lead to a similar behaviour as it would affect the scattering phase function also most strongly near the rainbow and backscatter peak. We note here that a similar behaviour in retrieved effective radii is also apparent at 1.6 and $2.1 \mu \mathrm{m}$ (not shown). 

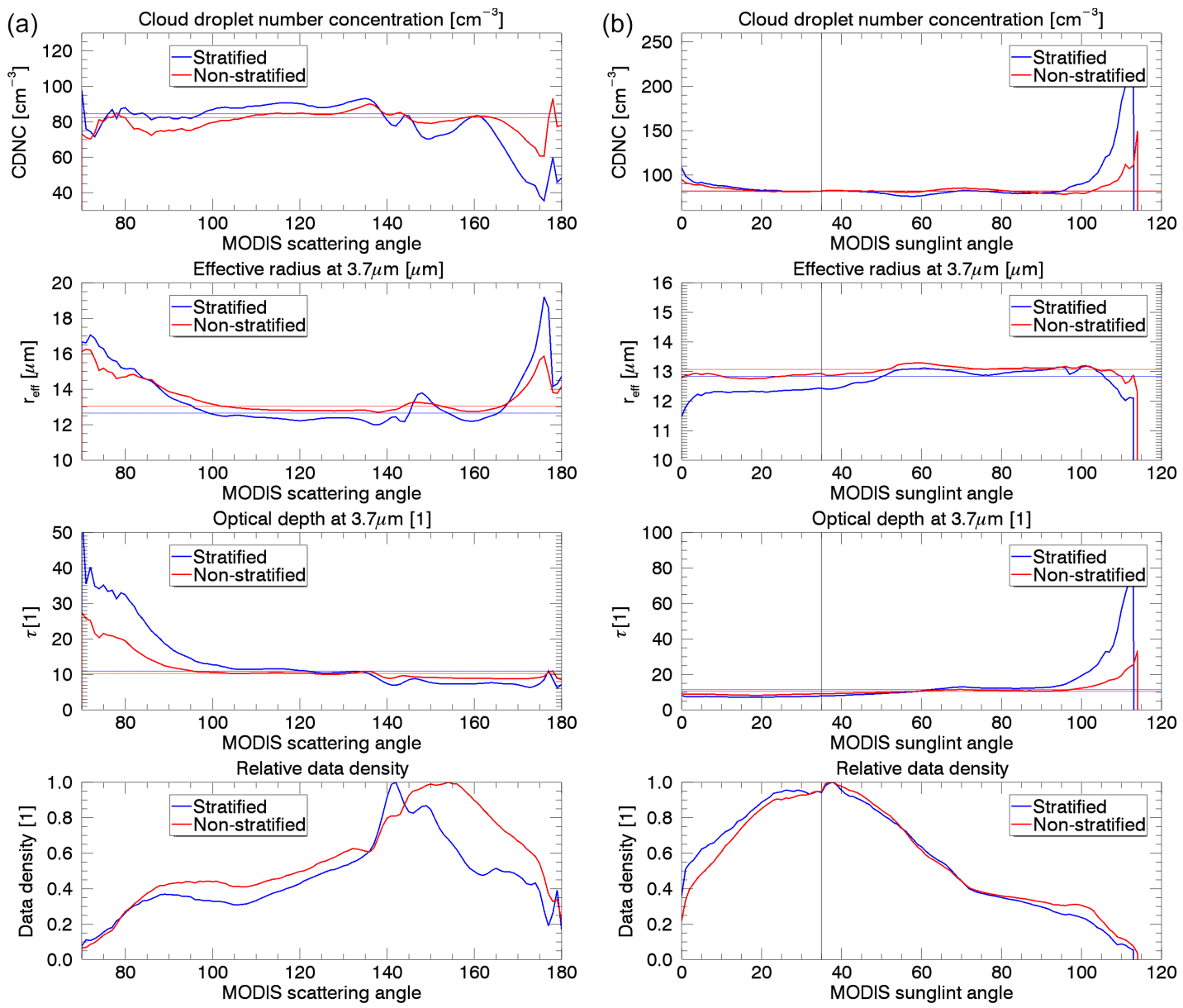

Figure 4. Dependency of retrieved CDNC, effective radius, and optical depth, all at $3.7 \mu \mathrm{m}$, on scattering angle (a) and sunglint angle (b) of Aqua-MODIS observations. The curves show global annual averages for the year 2008. See Table 1 for terminology regarding "Stratified" and "Non-stratified". The vertical line in the right panels shows the sunglint angle below which the MODIS cloud masks flag a sunglint contamination. The horizontal red and blue lines are the average retrieved values over the entire dataset.

- At scattering angles between 70 and about $100^{\circ}$, both effective radius and optical depth show above-average values, which likely are biases in the retrieval. These low scattering angles occur near the edge of the MODIS swath that is oriented toward the Sun. Since Aqua's local Equator crossing time is around 14:30, the Sun is toward the west of the satellite; therefore, the western edge of the scan is most strongly affected. Note that there are only relatively few observations at such low scattering angles. This region also loosely corresponds to the region with a low sunglint angle discussed next.

- In terms of sunglint angle (Fig. 4, right panels), dependencies can be observed at the low end of sunglint angles and, more strongly, at the high end of sunglint angles. The low end of sunglint angles occurs to the west of the swath, where the solar zenith angle equals the sensor zenith angle. High sunglint angles occur at the eastern scan edge. While some dependence on sunglint angle can be observed for low sunglint angles, the dominant variability on this (western) side of the swath appears to lie in the scattering angle dependency, which is dominated toward the scan edge by variations in the observer zenith angle. On the eastern side of the swath a similar picture emerges, with an strong increase in retrieved optical depth and, consequently, CDNC toward the (eastern) scan edge. For high sunglint angles the data density however is also relatively low.

To summarize, view angle dependencies are found toward both the eastern and western scan edges. Results here are largely consistent with earlier results reported in Maddux et al. (2010) and are likely caused by increasing field-ofview size and three-dimensional radiative transfer effects toward the edge of the scan. In addition, dependencies of retrievals on scattering angle are also found in the rainbow and backscattering of the phase function. These are likely caused by assumptions made in the retrieval process. From hereon 
Table 1. Terminology used to differentiate various screening tests performed on the Level-2 data.

\begin{tabular}{ll}
\hline Term used & Explanation \\
\hline Stratified & $\begin{array}{l}\text { All six screening criteria listed in Sect. } 2.3 \text { are } \\
\text { used. This is the screening used for the final } \\
\text { published climatology. }\end{array}$ \\
\hline $\begin{array}{l}\text { Non- } \\
\text { stratified }\end{array}$ & $\begin{array}{l}\text { Only screening criteria } 1-5 \text { listed in Sect. } 2.3 \\
\text { are used. Therefore, in contrast to "stratified", } \\
\text { the effective radii are not required to increase } \\
\text { monotonically between the } 1.6 \text { and } 3.7 \mu \text { m re- } \\
\text { trievals. }\end{array}$ \\
\hline Flagged & $\begin{array}{l}\text { In addition to screening criteria } 1-6 \text { in Sect. } 2.3, \\
\text { the aggregation process excluded observations } \\
\text { with a sunglint angle smaller than } 35^{\circ} \text { and scat- } \\
\text { tering angles smaller than } 95^{\circ} \text { or larger than } \\
165^{\circ} .\end{array}$ \\
\hline
\end{tabular}

forward we refer to all of these effects combined as "retrieval artefacts".

\subsection{Impact of stratification and retrieval artefacts on climatology}

Before we discuss the impact of retrieval artefacts on the climatology, we discuss the impact of the stratification on the CDNC climatology.

\subsubsection{Impact of stratification}

Figure 5 shows the mean relative difference "Stratified" versus "Non-stratified" for the year 2008. In the top panel only $1 \times 1^{\circ}$ grid boxes are shown where all 12 months have valid values for both "Stratified" and "Non-stratified". In particular in areas where broken clouds are frequently observed, the stratification criterion removes a significant number of observations, sometimes of the order of $90 \%$. Resulting differences in climatology are in general positive, with the exception of a narrow band in the tropical Pacific. Typically relative differences in mean CDNC climatology are smaller than $10 \%$, with a few exceptions off the eastern coasts of Asia and North America.

Figure 5 also shows the (2008) CDNC annual cycle for four selected areas. We selected areas where the differences between "Stratified" and "Non-stratified" are particularly large. The plots labelled PVG ("percentage of valid grid boxes") in Fig. 5 further show the percentage of valid $1 \times 1^{\circ}$ grid boxes in each region depending on which stratification criterion was used. The three different estimates of CDNC given in each of the regional mean CDNC panels in Fig. 5 can be interpreted as follows: deviations between the blue and red curves reflect differences in CDNC estimates for grid boxes where both "Stratified" and "Non-stratified" provide valid CDNC values. In contrast, deviations between the red and black curves include the additional effect of "Non-stratified" results being available in more grid boxes, thereby depending on PVG differences (red versus black); the black curve samples more grid boxes within a given region. For example, only about $10 \%$ of the grid boxes in region X12 provide valid CDNC values in the "stratified" case, whereas for "Nonstratified" about $90 \%$ of the grid boxes provide valid CDNC values. In this same region (X12) one can identify a secondary peak in "Non-stratified", the annual cycle in October that does not exist, if only grid boxes that hold valid stratified observations enter the regional averages. Thus, the apparent difference between the red and blue curves is caused by differences between the grid-box-averaged retrieved values for "Stratified" and "Non-stratified" and not just by "Nonstratified" seeing a different and larger sub-region of X12. Area $\mathrm{BC} 1$ shows an annual cycle offset by 2 months between the two climatologies. Similar to the secondary peak seen in $\mathrm{X} 12$, this offset in annual cycle is not caused by different grid boxes within the region being populated, as the black and blue curves are nearly on top of each other.

In contrast, area R05 shows in general much lower CDNC and also a decreased annual cycle if the stratification criterion is not applied (black versus red curve). However, if the dataset is limited to only those areas where stratified results are available, these differences are less pronounced (blue versus red curve), indicating that the differences seen between the black and red curves for R05 are largely caused by "nonstratified" sampling of a larger sub-area of R05. In summary, we find that deviations in mean value between "Stratified" and "Non-stratified" are small but largely systematic globally. Further, the annual cycle of CDNC can be strongly affected, depending on the area observed.

\subsubsection{Impact of retrieval artefacts}

Figure 6 shows the impact of the above-discussed retrieval artefacts on the CDNC climatology. The interpretation of the different curves in Fig. 6 is similar to the interpretation discussed for Fig. 5 in Sect. 4.2.1, except that Fig. 6 compares the "stratified" results used in the final climatology with "flagged results" in which sampling was only performed for observation geometries that did not show large variations in retrieved effective radius and optical depth (see Sect. 4.1 and Table 1). The additional constraints on observation geometry significantly reduce spatial coverage, as can be seen in the upper panel of Fig. 6 as well as in the PVG plots for the individual regions also shown in Fig. 6. The relative difference in CDNC between "flagged" and "stratified" is less than $10 \%$. The annual cycles for the four selected areas also discussed under Sect. 4.2.1 are very similar between "flagged" and "stratified". An exception to this is R03, where the "flagged" results show an enhanced annual cycle over the "stratified" results but do not show a shift in an annual cycle. This enhanced annual cycle appears to be caused solely by the difference in coverage between "flagged" and "strat- 

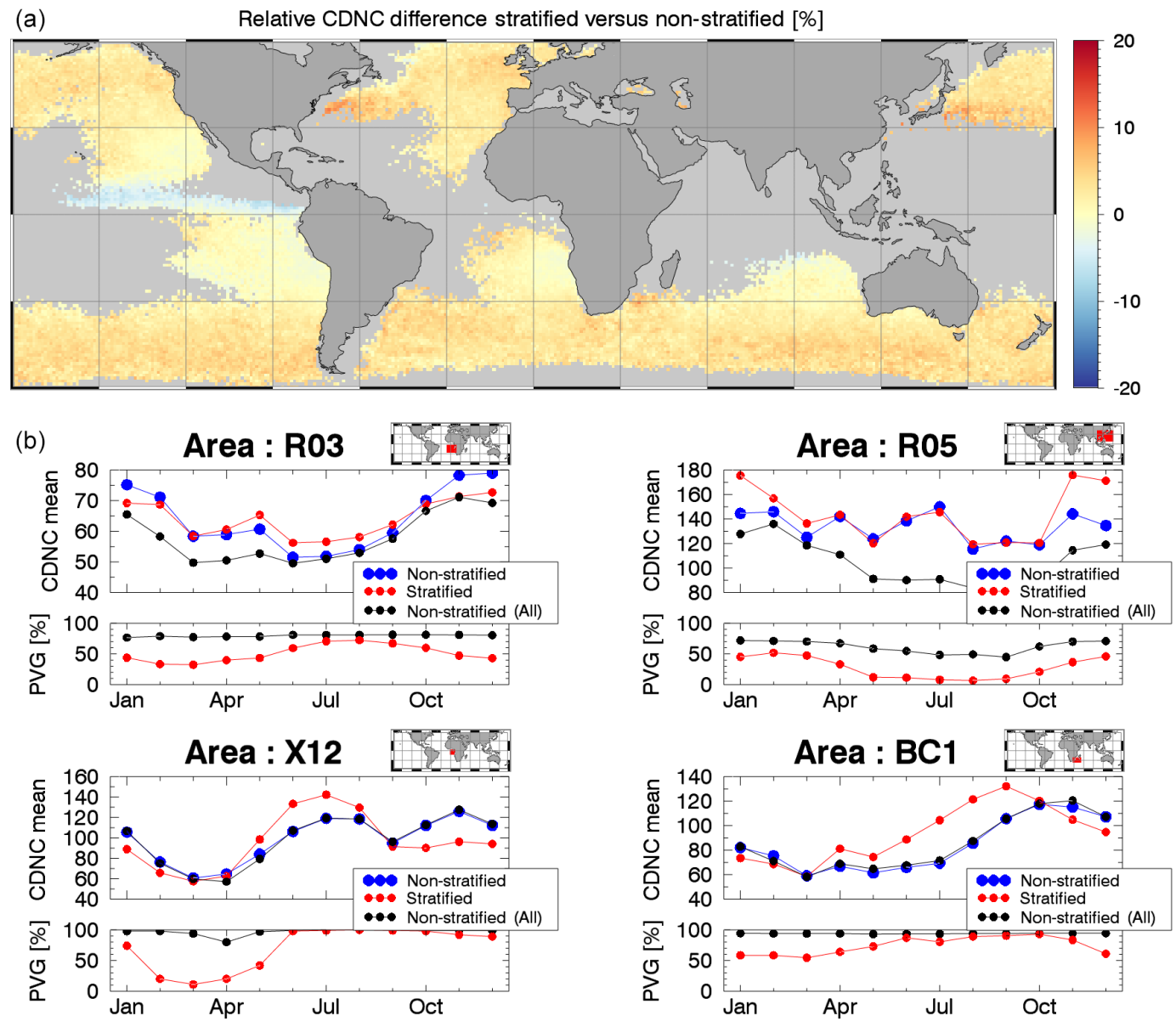

Figure 5. Comparison of results for 2008 for "Stratified" versus "Non-stratified" climatologies. See Table 1 for terminology. Panel (a) shows the relative difference in 2008 mean CDNC between "stratified" and "non-stratified". Panel (b) shows the annual cycle of CDNC for four selected regions where differences between "stratified" and "non-stratified" were particularly strong. The figures also show the "percentage of valid grid points", labelled "PVG". PVG corresponds to the number of $\left(1 \times 1^{\circ}\right)$ grid points in a region that have valid CDNC estimates, divided by the total number of grid points in that region times 100. The three different annual cycles in CDNC correspond to region-wide averages over all grid boxes with valid "non-stratified" CDNC estimates (black); averages over all grid boxes with valid "stratified" CDNC estimates (red); and averages of non-stratified estimates only over those grid boxes where "stratified" CDNC estimates are also available (blue). For details on the selected regions, see also Table 3.

ified". If the averages for R03 are confined to grid boxes where flagged results are also available (blue curve), those are nearly identical again to the red curve. Other selected areas (not shown) substantiate these findings, i.e. the relative differences between "flagged" and "stratified" are small, the annual cycle appears not to be affected, but the magnitude of the annual cycle is somewhat muted in the "stratified" cases (caused by differences in the number of valid $1 \times 1^{\circ}$ grid boxes per region between "flagged" and "stratified"). Clearly, while some of the retrieval artefacts discussed in Sect. 4.1 propagate through into the climatology, their impact is somewhat reduced by averaging out the strong observation geometry dependencies seen in the Level-2 data (Sect. 4.1) when the monthly $1 \times 1^{\circ}$ mean values are aggregated. Recall also that the retrieval artefacts cannot easily be corrected for without potentially re-deriving new Level-2 cloud optical property retrievals. While a restriction of the climatology to "flagged" results would ameliorate some of the impact of the retrieval artefacts, it would at the same time severely limit the climatology spatially. Weighing these different aspects, we opted in favour of increased spatial coverage.

\subsection{Assessment versus Vocals-Rex in situ observations}

To assess the robustness of the CDNC retrievals in this study, the results were compared to the in situ CDNC observations of Painemal and Zuidema (2011), hereafter referred to as PZ11. Twenty profile-averaged CDNC measurements were collected in 2008 during the VAMOS Ocean-CloudAtmosphere-Land Study Regional Experiment (VOCALSRex) coincident with Aqua and Terra overpasses. The PZ11 


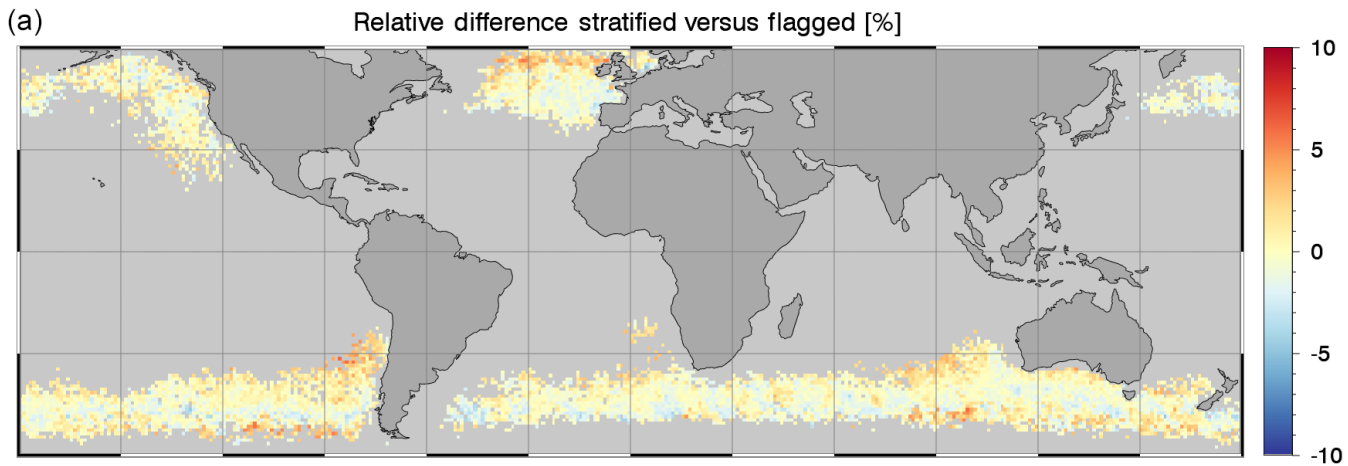

(b)
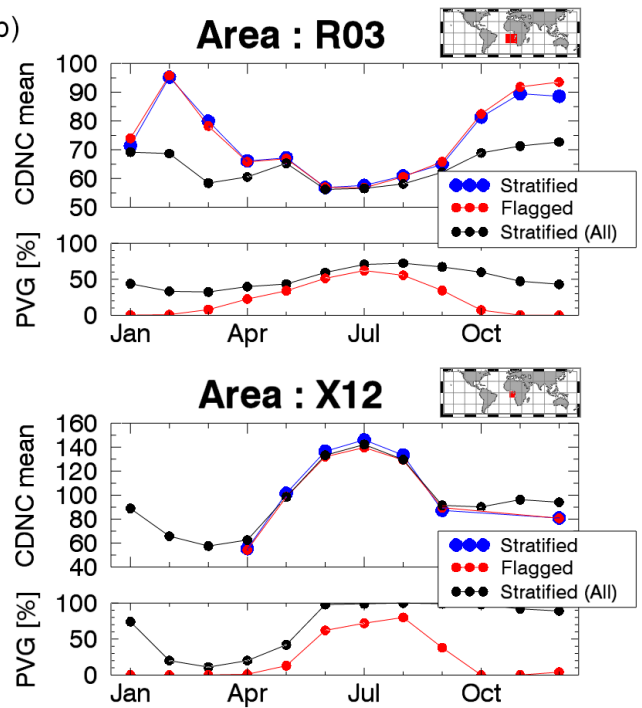
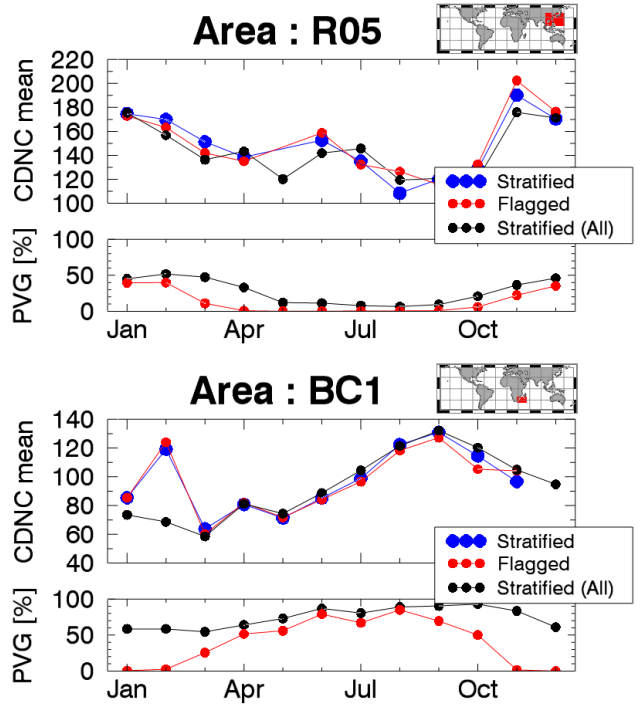

Figure 6. Same as Fig. 5 but for "Stratified" versus "Flagged"; see Table 1 for terminology. For details on the selected regions, see also Table 3.

CDNC estimates were derived from the profile average of the onboard cloud droplet probe. Details on the sampling strategy are given in PZ11. Here we compare individual MODIS CDNC retrievals as well as areal averages of MODIS CDNC retrievals to the in situ derived CDNC values from PZ11. Nearest neighbour (NN) MODIS observations were found spatially, corresponding to each profile's latitude and longitude as reported in PZ11. Temporally, either Aqua-MODIS or Terra-MODIS was used, depending on the observation time reported in PZ11. In addition to the NNs, spatial averages of MODIS observations over $21 \times 21$ and $51 \times 51$ pixels were also used, corresponding to areal extents of $0.2 \times 0.2$ and $0.5 \times 0.5^{\circ}$, respectively, at nadir. The approach was performed independently for both stratified and non-stratified retrieval selections. For the non-stratified NN cases, the nearest pixel was generally within $2 \mathrm{~km}$ of the profile location. When considering stratified nearest neighbours, the distance tends to increase, which may decrease coherence, but most stratified observations were within $10 \mathrm{~km}$ of the profiled cloud. Results are presented in Fig. 7 and Table 2.
Regardless of grid-box size and whether or not the stratification criterion was applied, the comparisons between in situ and remotely sensed CDNC show high correlations and biases of the order of at maximum $10 \%$ of the mean retrieved CDNC values. The non-stratified results show a generally good agreement with PZ11, with almost negligible bias and root mean square errors less than $25 \mathrm{~cm}^{-3}$. For the stratified results, magnitudes of the RMSE and bias increase but are generally also in agreement with PZ11. One possible explanation for the larger bias observed in the stratified cases relates to the fact that cases observed by PZ11 are very thin and hence the three effective radii are very close to each other. Random noise on top of the retrievals might in some cases lead to the $3.7 \mu \mathrm{m}$ effective radius being smaller than the $2.1 \mu \mathrm{m}$ effective radius. These cases would be excluded, thereby favouring cases where $3.7 \mu \mathrm{m}$ is positively biased. This would lead to a negative bias in CDNC as observed to be caused by the combination of random noise and the selection criterion chosen. While the dataset compiled by PZ11 is extremely helpful, it is not globally representative. More in situ comparisons covering a wider variety of clouds and 

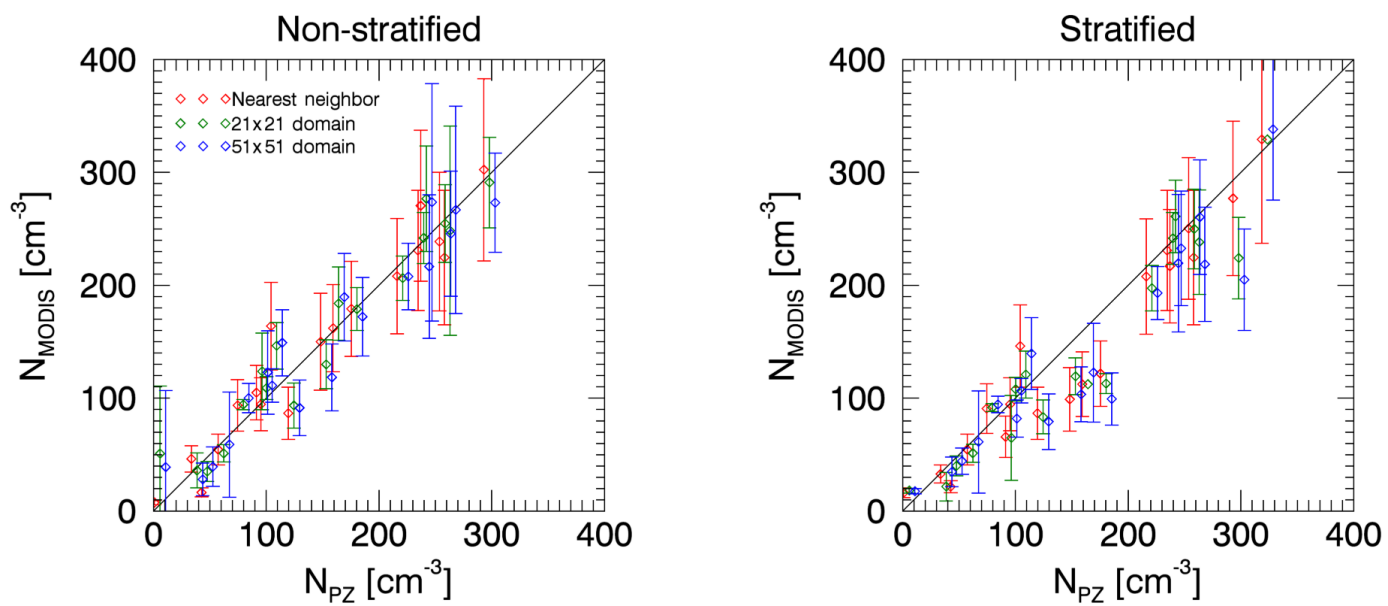

Figure 7. Scatter plot between PZ11-reported airborne and satellite-based derived CDNC estimates, corresponding to the statistics shown in Table 2. Uncertainty for nearest neighbours is estimated using Gaussian error propagation of uncertainties of effective radius and optical depth reported in MODIS C6. Uncertainties for the $21 \times 21$ and $51 \times 51$ domains are estimates as the standard deviation of all valid CDNC retrievals within the domains. Note that for each data point the $x$-axis values of the $\mathrm{NN}, 21 \times 21$, and $51 \times 51$ are slightly offset around the (green) centre value, in order to be able to better visually discriminate the error bars. See Table 1 for terminology regarding "Stratified" and "Non-stratified".

Table 2. Statistics of comparison between PZ11-reported airborne and satellite-based derived CDNC estimates, corresponding to the scatter plots shown in Fig. 7. The columns marked "N" refer to "Non-stratified" case, whereas the columns marked "S" refer to the "Stratified" case. The reported uncertainty is the mean value of the error bars seen in Fig. 7.

\begin{tabular}{lrr|rr|r|r|r|rr}
\hline Domain & $\begin{array}{c}\text { RMSE } \\
\left(\mathrm{cm}^{-3}\right)\end{array}$ & \multicolumn{2}{c|}{$\begin{array}{c}\text { Bias } \\
\left(\mathrm{cm}^{-3}\right)\end{array}$} & Correlation & \multicolumn{2}{|c|}{$\begin{array}{c}\text { Uncertainty } \\
\left(\mathrm{cm}^{-3}\right)\end{array}$} \\
\cline { 2 - 9 } & $\mathrm{N}$ & $\mathrm{S}$ & $\mathrm{N}$ & $\mathrm{S}$ & $\mathrm{N}$ & $\mathrm{S}$ & $\mathrm{N}$ & $\mathrm{S}$ \\
\hline Nearest neighbour & 22.1 & 29.7 & -2.7 & -17.3 & 0.97 & 0.97 & 36.7 & 35.6 \\
$21 \times 21$ & 21.6 & 31.7 & 3.8 & -16.9 & 0.97 & 0.96 & 28.3 & 19.8 \\
$51 \times 51$ & 23.1 & 37.4 & 1.1 & -18.7 & 0.96 & 0.94 & 42.1 & 31.5 \\
\hline
\end{tabular}

observation geometries are needed to further elucidate such effects on retrievals globally.

Results for the average $51 \times 51$ and $21 \times 21$ domain cases show results similar to the single pixel cases in terms of biases and RMSE values. However, for both $51 \times 51$ and $21 \times 21$ neighbourhoods, the mean uncertainty (size of error bars in Fig. 7 and last two columns in Table 2) is reduced for the stratified cases over the non-stratified cases. Recall that the mean uncertainty reported for these two neighbourhoods is the standard deviation of all valid CDNC retrievals in the respective averaging box. Effective radius stacking is likely decreasing the selection of pixels of inhomogeneous clouds or those subject to sub-pixel effects, which, as discussed in Sect. 3, can result in retrievals with a wide spread of unphysical effective radii.

Finally, we note that the uncertainties of the NN approach were calculated using Gaussian error propagation using the reported effective radius and optical thickness errors in the MODIS Collection 6 data following the approach in Bennartz (2007). One can see that the so-derived uncer- tainties are of about the same magnitude as the uncertainties derived from the standard deviations of the $21 \times 21$ and $51 \times 51$ boxes. This analysis holds true also for larger box sizes and a wider variety of cases, as shown below.

\subsection{Uncertainty estimates}

As outlined in Sect. 2.3, two main pathways exist for the definition of uncertainties associated with the climatology. Firstly, uncertainties in retrieved effective radius and optical depth reported in the MODIS Collection 6 Level-2 product can be propagated forward to yield Level-2 uncertainties in CDNC. All auxiliary parameters in the retrieval (i.e. $c_{\mathrm{W}}$, $Q$, and $k$ in Eq. 2) were assigned the same uncertainties as in Bennartz (2007), that is, $k=0.8 \pm 0.1, Q=2 \pm 0.1$, and $c_{\mathrm{W}}=(0.8 \pm 0.1) \times f(\mathrm{CTT})$. We note here that these parameters as well as the MODIS Level-2 uncertainties reported for effective radius and optical depth retrievals are not fully random and might contain bias components that are difficult to quantify without independent validation information. 
The uncertainties calculated via error propagation therefore do not strictly separate the effect of random versus systematic errors. We note further that the combined contribution of $k, Q$, and $c_{\mathrm{w}}$ to the total uncertainty in CDNC is only around $15 \%$ (Bennartz, 2007), so that retrieval errors in optical depth and effective radius dominate the error budget for CDNC. Furthermore, some possible error sources are not included in the MODIS Level-2 effective radius and optical depth reported in the MODIS Level-2 Collection 6 data (e.g. the effects of sub-scale inhomogeneity are not included; Platnick et al., 2017). Therefore, while instructive, CDNC uncertainties based on error propagation might underestimate the true uncertainty even of individual Level-2 retrievals.

A second way of characterizing uncertainty in the monthly-mean CDNC estimates is to calculate the standard deviation of all Level-2 observations within a given $1 \times 1^{\circ}$ box. The standard deviation would include the synoptic variability of CDNC as well as all actual random retrieval uncertainties and should in any case be larger than the uncertainty derived from error propagation. However, the standard deviation would fail to capture any systematic errors that are consistent throughout the spatial averaging range $\left(1 \times 1^{\circ}\right)$ and time period (1 month). Uncertainty estimates based on standard deviation therefore also likely underestimate the true variability of the mean CDNC. However, in contrast to the uncertainty estimates based on error propagation, they fully account for all truly random sources of variability, including e.g. random fluctuations in cloud sub-scale inhomogeneity at the individual pixel level.

Here, we compare these two measures (error propagation versus standard deviation). Recall from Sect. 2.3 that the monthly uncertainties for each grid box were calculated as the square root of the mean of the daily uncertainties over the course of each month, thereby following the approach used in NASA's Level-3 gridded MODIS cloud product (Hubanks et al., 2016). Figure 8 compares the two different uncertainty estimates in terms of the relative uncertainty averaged over the entire year of 2008. Except for some stratocumulus regions, the uncertainty estimate based on the standard deviation of the individual Level-2 observations is significantly larger than the uncertainty based on error propagation. This would be consistent with monthly uncertainties driven by synoptic variability. However, for some of the stratocumulus areas, outlined with black isolines in the bottom panel of Fig. 8, the uncertainty by standard deviation is smaller (by up to $50 \%$ ) than the uncertainty by forward propagation of retrieval errors. Hypothetically, and ignoring systematic errors in the discussion of error propagating, even if the actual CDNC in those areas was perfectly constant spatially and temporarily, the uncertainty by standard deviation would be identical to the uncertainty by forward-propagated retrieval error. The only scenario under which this situation could be reversed would be if estimated uncertainties feeding into the theoretical forward propagation are too large. For example, if the reported uncertainty of the effective radius in the
MODIS Level-2 product were too large, this would lead to overly large uncertainties in the propagated CDNC uncertainty. Thus, from the bottom panel of Fig. 8, it would appear that the forward propagated uncertainties for individual CDNC retrieval are slightly too large. That is, we put slightly less trust in the Level-2 observations than appears to be warranted by this comparison.

For the practical matter of characterizing uncertainty associated with CDNC retrievals for the gridded product, the reported uncertainty estimates should include the impact of day-to-day variability in order to allow for a realistic estimate of the true variability of CDNC. In the final CDNC climatology we therefore report the standard deviation of the retrieved CDNC values within each $1 \times 1^{\circ}$ grid box as an uncertainty estimate. It is important to note that this measure of uncertainty only addresses random errors and does not address possible systematic errors. Such possible systematic errors are better discussed in the framework of sensitivity studies as for example outlined in Sect. 4.2.2 for the case of retrieval artefacts.

\section{Climatological results}

\subsection{Global overview}

Figures 9 and 10 show a global overview of the CDNC climatology. The upper two panels of Fig. 9 show mean CDNC and relative uncertainty for the entire time period. The lowermost panel of Fig. 9 shows the fraction of months with missing data. One can see that mean CDNC is typically high near the coasts, in particular downwind of the major continents, and lower over the remote oceans. In particular in the tropics certain areas exhibit very low data coverage. Areas in the northern Indian Ocean and the western Pacific exhibit no valid data at all. These areas are typically associated with convective regions where the ISBLC assumption frequently breaks down because either isolated cumuli or deep convection are observed. Near the fringe of these regions the largest relative uncertainties are also observed. Over the mid-latitude storm tracks as well as over the traditional stratocumulus areas west of the major continents, data coverage is higher and various regions show full coverage for all months. Relative uncertainty is of the order of 60 to $80 \%$ in the storm tracks and increases polewards. In the stratocumulus regions the relative uncertainty is about $30 \%$. Recall that uncertainties are calculated as the square root of the mean of the daily $1 \times 1^{\circ}$ variances over the course of each month, thereby assuming uncertainties between days to be uncorrelated (see Sect. 2.3). The reported uncertainties are however very similar to the a posteriori uncertainties derived from error propagation (see Sect. 4.3 and 4.4). 

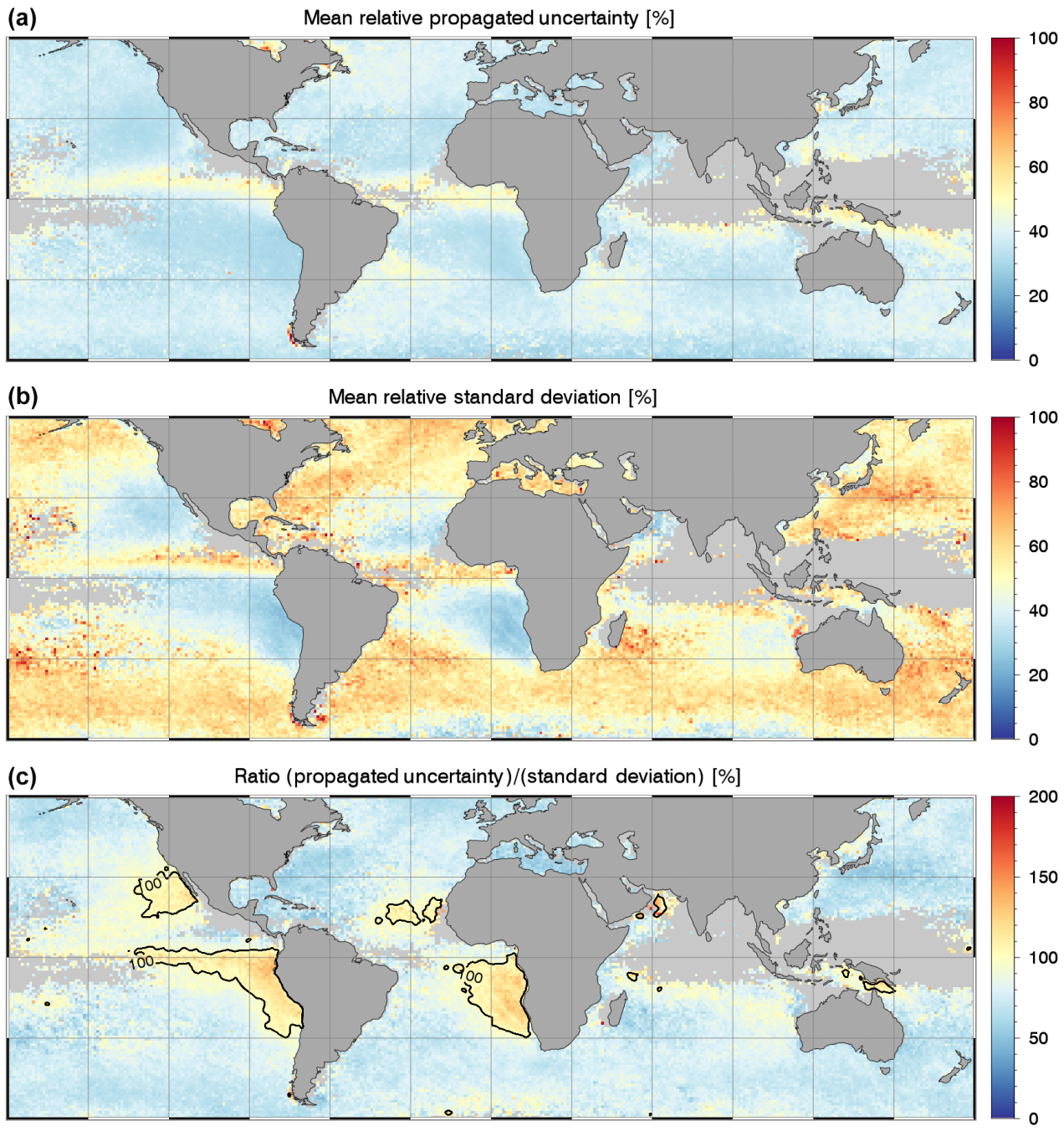

Figure 8. Panel (a) shows the mean uncertainty of the $1 \times 1^{\circ} \mathrm{CDNC}$ estimates calculated via error propagation based on retrieval errors reported for the MODIS effective radius and optical depth products and following the methodology outlined in Bennartz (2007). Panel (b) shows the mean relative standard deviation of all Level- 2 CDNC retrievals that contribute to a $1 \times 1^{\circ}$ average. Panel (c) shows the ratio of these two quantities.

Figure 10 shows information on the annual cycle of CDNC. The data density in Fig. 10 is lower than in Fig. 9 because we only included grid boxes where a full annual cycle was available. For some areas, in particular in the tropics, data were only available for certain months, and these grid boxes were excluded from the annual cycle analysis. The upper panel of Fig. 10 shows the amplitude of the annual cycle both colour-coded and as isolines. Amplitude here is defined as the amplitude of a cosine fit of the annual cycle of CDNC. These same isolines are over-plotted also over the other two panels of Fig. 10. The strongest annual cycle is found off the coast of China and off the eastern coast of North and South America. Strong annual cycles are also found in the stratocumulus regions off the western coast of South America and Australia and, to a lesser, extent, off the western coast of
Africa. In all of these regions with a strong annual cycle a large fraction of the CDNC variability is explained by simple cosine fits. In contrast, certain areas in the North Atlantic and off southern Africa show a more complicated behaviour, although the annual variability there is lower (for examples, see Fig. 11). The lowermost panel of Fig. 10 shows the month of the peak CDNC. The month of peak CDNC varies greatly depending on region. Subsequently we discuss and highlight some of the regions in more detail.

\subsection{Regional results}

We present regional results for a variety of different areas that have been discussed in the literature (see Fig. 9 for details). We present results in terms of mean CDNC as well as trends 


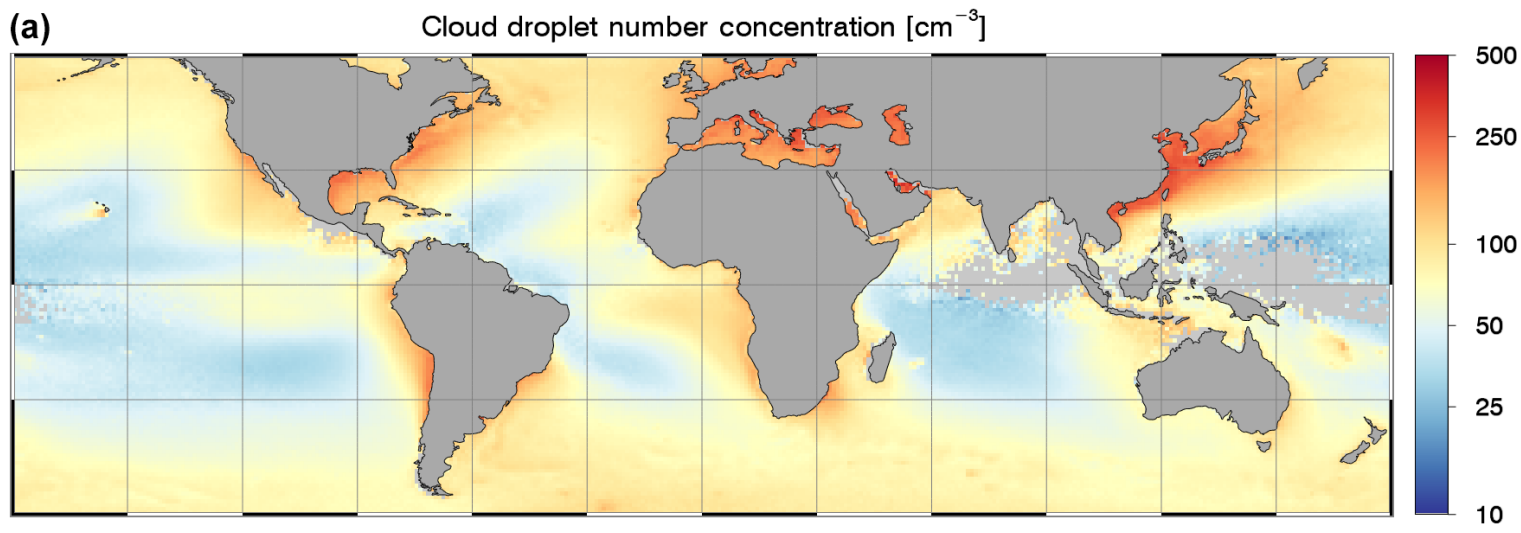

(b) Mean relative standard deviation [\%]

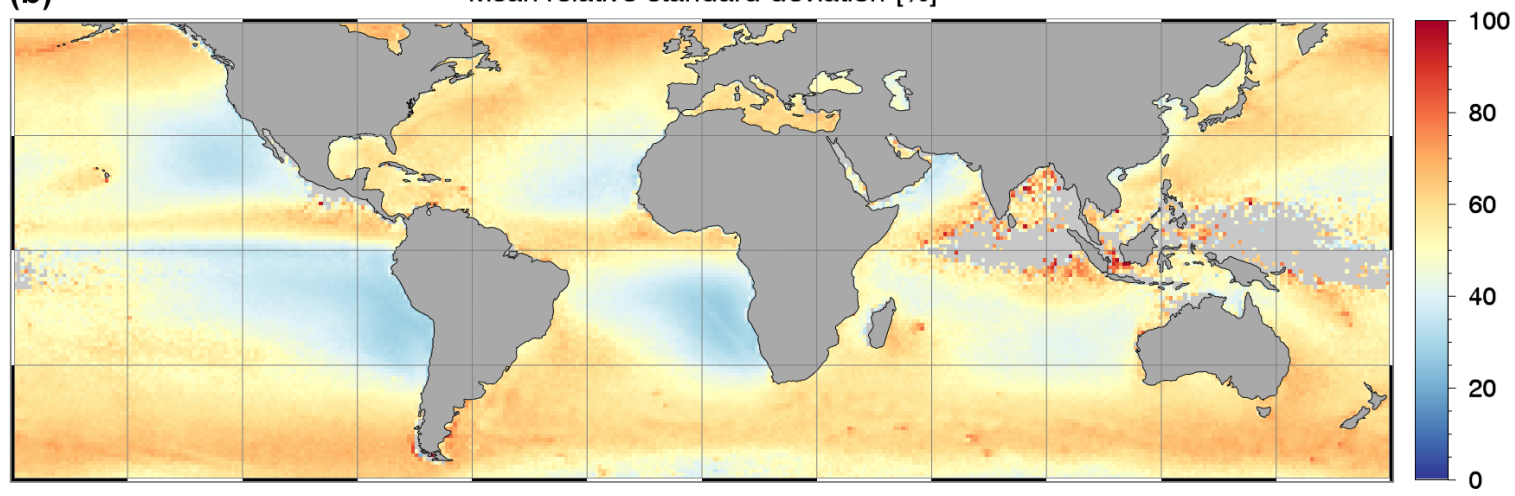

(c) Fraction of months with missing data [\%]

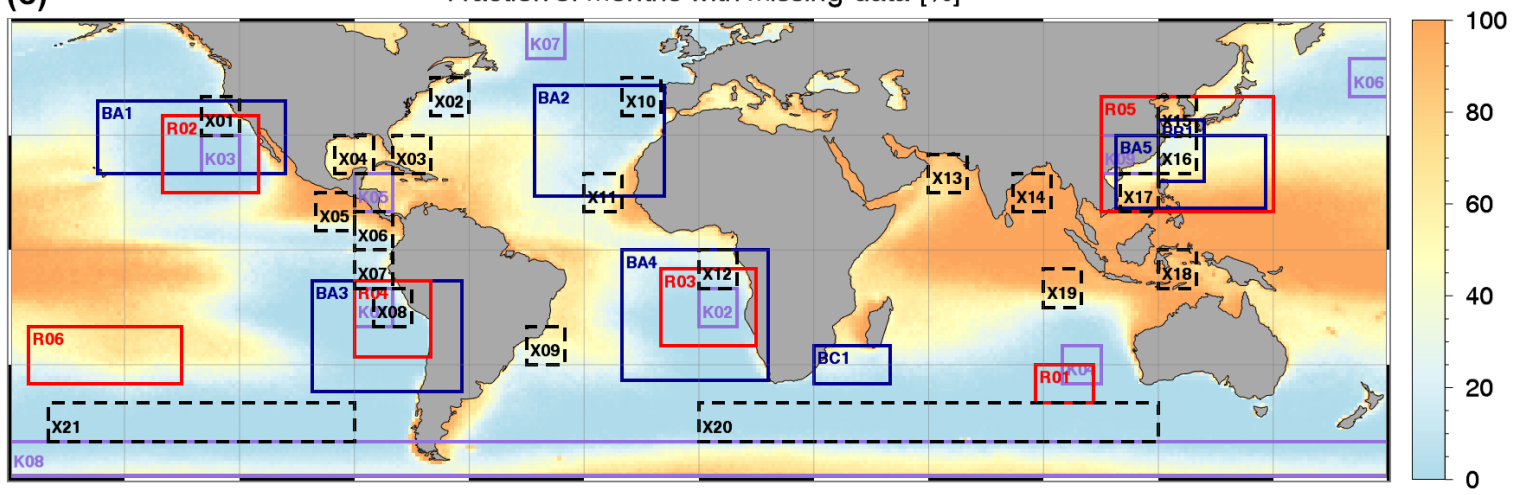

Figure 9. Panel (a) shows the mean CDNC over the period 2003-2013. Panel (b) shows the mean relative spatial standard deviation of the CDNC estimates and panel (c) shows the fraction of months with missing data in the climatology. Areas BA1-BA7 are defined in Bennartz (2007), BB1 in Bennartz et al. (2011), BC1 in this publication, K01-K09 in Klein and Hartmann (1993), R01-R06 in Rausch et al. (2010), and X01-X21 in Zhao et al. (2016). The corresponding latitude-longitude boundaries are also listed in Table 3.

in Table 3. In addition we show the time series as well as the average annual cycle for selected areas in Fig. 11.

\subsubsection{Remote areas}

We categorize as remote areas the areas R01, R06, K08, $\mathrm{X} 20$, and $\mathrm{X} 21$, the last three of which are also shown in Fig. 11. The areas are sufficiently remote to be not strongly affected by anthropogenic changes in aerosol conditions to serve as a check for the temporal stability of the dataset. In- deed, for none of these areas are trends in CDNC larger than $\pm 3 \mathrm{~cm}^{-3}(10 \mathrm{yrs})^{-1}$, and none of trends are even remotely statistically significantly different from zero. We therefore conclude that the baseline of the climatology appears to be robust and the underlying MODIS observations do not exhibit any serious trends. Such trends could for example have been caused by slight changes in absolute calibration or other sensor-specific issues. 
Table 3. For all areas shown in Fig. 9, this table lists the latitude-longitude boundaries, mean CDNC, standard deviation of CDNC, regression slope of CDNC against time, and the statistical significance of the slope. Rows in bold font have a significance level higher than $95 \%$. The regression slope was calculated on monthly CDNC anomalies. The monthly CDNC anomalies were calculated by subtracting from each individual month the 13-year mean value of that same month.

\begin{tabular}{|c|c|c|c|c|c|c|c|c|}
\hline Area & $\begin{array}{r}\text { Left lon } \\
{ }^{\circ} \mathrm{E}\end{array}$ & $\begin{array}{r}\text { Right lon } \\
{ }^{\circ} \mathrm{E}\end{array}$ & $\begin{array}{r}\text { Lower lat } \\
{ }^{\circ} \mathrm{N}\end{array}$ & $\begin{array}{r}\text { Upper lat } \\
{ }^{\circ} \mathrm{N}\end{array}$ & $\begin{array}{l}\text { Mean } \\
\mathrm{cm}^{-3}\end{array}$ & $\begin{array}{r}\mathrm{SD} \\
\mathrm{cm}^{-3}\end{array}$ & $\begin{array}{r}\text { Slope } \\
\mathrm{cm}^{-3} 10 \mathrm{yr}^{-1}\end{array}$ & $\begin{array}{r}\text { Stat. sig. } \\
\%\end{array}$ \\
\hline X01 & -130 & -120 & 30 & 40 & 98.3 & 16.4 & -8.1 & 69.3 \\
\hline X02 & -70 & -60 & 35 & 45 & 140.5 & 25.2 & -50.5 & 100.0 \\
\hline X03 & -80 & -70 & 20 & 30 & 91.5 & 20.1 & -31.7 & 98.6 \\
\hline X04 & -95 & -85 & 20 & 30 & 127.8 & 20.2 & -28.7 & 95.0 \\
\hline X05 & -100 & -90 & 5 & 15 & 63.6 & 7.4 & 2.9 & 55.8 \\
\hline X06 & -90 & -80 & 0 & 10 & 72.4 & 10.1 & -0.4 & 5.3 \\
\hline X07 & -90 & -80 & -10 & 0 & 92.0 & 8.8 & -10.9 & 93.7 \\
\hline X08 & -85 & -75 & -20 & -10 & 97.1 & 9.9 & -9.9 & 95.5 \\
\hline X09 & -45 & -35 & -30 & -20 & 93.1 & 15.8 & -5.5 & 56.1 \\
\hline X10 & -20 & -10 & 35 & 45 & 101.2 & 21.5 & -17.9 & 89.5 \\
\hline X11 & -30 & -20 & 10 & 20 & 70.7 & 7.5 & -4.1 & 76.0 \\
\hline $\mathrm{X} 12$ & 0 & 10 & -10 & 0 & 98.9 & 10.4 & -5.3 & 65.3 \\
\hline X13 & 60 & 70 & 15 & 25 & 94.1 & 12.2 & 0.9 & 9.1 \\
\hline X14 & 82 & 92 & 10 & 20 & 83.9 & 13.4 & -6.4 & 39.2 \\
\hline X15 & 120 & 130 & 30 & 40 & 240.0 & 21.3 & -19.5 & 96.7 \\
\hline X16 & 120 & 130 & 20 & 30 & 165.6 & 20.3 & -16.6 & 87.1 \\
\hline X17 & 110 & 120 & 10 & 20 & 98.4 & 19.0 & -20.9 & 92.2 \\
\hline X18 & 120 & 130 & -10 & 0 & 67.1 & 11.1 & -2.5 & 18.1 \\
\hline X19 & 90 & 100 & -15 & -5 & 48.0 & 8.4 & -1.4 & 23.8 \\
\hline $\mathrm{X} 20$ & 0 & 120 & -50 & -40 & 74.2 & 5.0 & -3.1 & 74.0 \\
\hline $\mathrm{X} 21$ & -170 & -90 & -50 & -40 & 64.7 & 4.7 & -1.8 & 51.3 \\
\hline R01 & 88 & 103 & -40 & -30 & 53.8 & 5.0 & -3.1 & 76.7 \\
\hline R02 & -140 & -115 & 15 & 35 & 85.0 & 10.1 & -8.6 & 86.8 \\
\hline R03 & -10 & 15 & -25 & -5 & 89.5 & 9.8 & -6.8 & 87.1 \\
\hline R04 & -90 & -70 & -28 & -8 & 90.3 & 8.1 & -6.9 & 93.9 \\
\hline R05 & 105 & 150 & 10 & 40 & 136.9 & 11.1 & -15.6 & 99.0 \\
\hline R06 & -175 & -135 & -35 & -20 & 45.4 & 4.2 & -1.7 & 59.3 \\
\hline BA1 & -157 & -108 & 20 & 39 & 74.6 & 7.6 & -7.4 & 92.0 \\
\hline BA2 & -43 & -9 & 14 & 43 & 74.6 & 8.0 & -8.8 & 95.4 \\
\hline BA3 & -101 & -62 & -37 & -8 & 69.2 & 5.5 & -4.1 & 89.2 \\
\hline BA4 & -20 & 18 & -34 & 0 & 76.3 & 6.8 & -4.2 & 84.0 \\
\hline BA5 & 109 & 148 & 11 & 30 & 107.7 & 12.5 & -9.3 & 82.0 \\
\hline BB6 & 120 & 132 & 18 & 34 & 169.6 & 17.0 & -17.1 & 96.0 \\
\hline $\mathrm{BC} 1$ & 30 & 50 & -35 & -25 & 95.9 & 11.1 & 0.6 & 10.0 \\
\hline K01 & -90 & -80 & -20 & -10 & 68.5 & 8.4 & -4.7 & 75.2 \\
\hline K02 & 0 & 10 & -20 & -10 & 98.7 & 12.3 & -7.8 & 79.7 \\
\hline K03 & -130 & -120 & 20 & 30 & 91.5 & 13.1 & -7.7 & 70.9 \\
\hline K04 & 95 & 105 & -35 & -25 & 52.0 & 5.7 & -0.4 & 11.0 \\
\hline K05 & -90 & -80 & 10 & 20 & 78.5 & 12.1 & -9.9 & 80.0 \\
\hline K06 & 170 & 180 & 40 & 50 & 92.0 & 13.0 & -3.6 & 43.2 \\
\hline K07 & -45 & -35 & 50 & 60 & 98.3 & 13.3 & -12.4 & 90.6 \\
\hline K08 & -180 & 180 & -59 & -50 & 81.5 & 4.1 & 0.9 & 23.5 \\
\hline K09 & 105 & 120 & 20 & 30 & 188.8 & 25.2 & -25.5 & 90.1 \\
\hline
\end{tabular}

\subsubsection{South-eastern Atlantic (off southern Africa) and south of Madagascar}

The Atlantic region off southern Africa has been widely studied in the context of biomass burning and the potential impact of biomass burning aerosols on clouds via the first aerosol effect (Bennartz, 2007; Wilcox et al., 2009; Painemal et al., 2014). Notably, the annual cycle of CDNC peaking in July appears to be a persistent feature in CDNC climatologies (see Fig. 10 and also area X12 in Fig. 11) that is consistent with southern African biomass burning. Peak anthropogenic biomass burning does not coincide with the height of the dry 

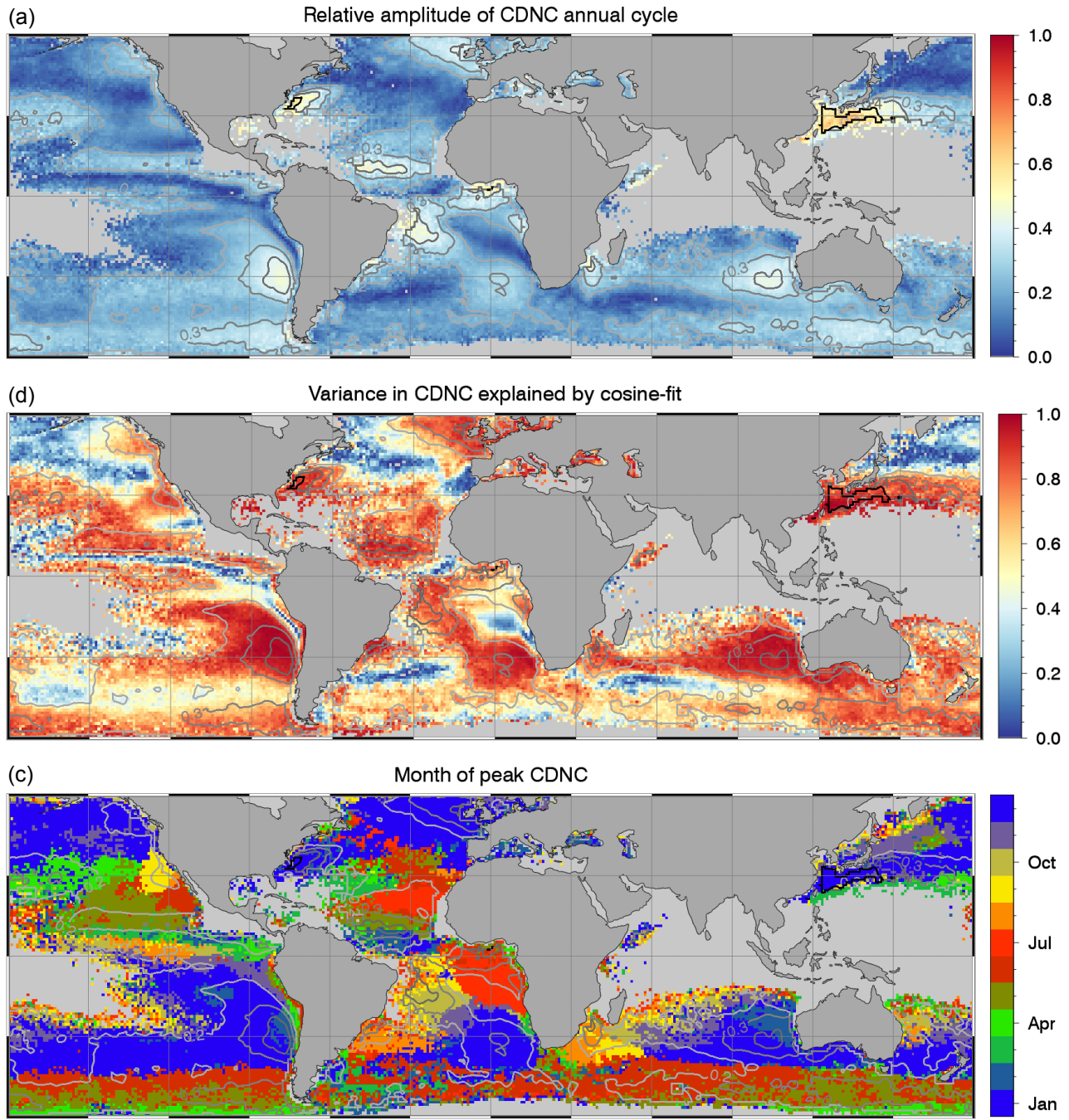

Figure 10. Panel (a) shows the relative magnitude of the 13-year mean annual cycle of CDNC. Panel (b) shows the variance explained by a simple cosine fit of the 13-year mean annual cycle. Panel (c) shows the months of the occurrence of the maximum CDNC. The isolines in all three plots show the relative magnitude of the CDNC annual cycle (same as panel (a)).

season, but does coincide with the middle of the burning season over the northern parts of Angola, the Democratic Republic of Congo, and Zambia, where savannah fires are often lit in July/August well before the peak of the dry season (Le Page et al., 2010). This picture is substantiated by individual fire counts based on geostationary satellite observations, which also shows peak fire activity around July/August, with peak burning of about $6 \mathrm{Tg}$ per day in July (Roberts et al., 2009). In contrast, in the eastern part of South Africa and Mozambique as well as northern Namibia, the middle of the fire season is shifted toward September. Depending on largescale weather patterns, biomass burning aerosol can be transported westwards over the southern Atlantic or eastwards over the southern Indian Ocean (see e.g. Sinha et al., 2003). With the biomass burning season in south-eastern Africa and Madagascar peaking in September, one would expect to find the annual cycle in CDNC also peaking around that time, and indeed the climatology does show exactly this (see Fig. 10 and also area BC1 in Fig. 11).

\subsubsection{East China Sea}

Various authors have studied the East China Sea in one form or another (see Fig. 9, R05, BA5, BB1, X15 (shown in Fig. 11), X16, and X17). It is interesting to see that over the observation period of the current study all of these areas exhibit a negative trend, often statistically significant, in CDNC for the period 2003-2013, which is opposite to the positive trend in CDNC reported for area $\mathrm{BB} 1$ and the period 1982-2010 (Bennartz et al., 2011). In that earlier publication we also established a causal link between the Chinese $\mathrm{SO}_{2}$ emissions and wintertime CDNC over the East China Sea. We speculate that decreases in Chinese $\mathrm{SO}_{2}$ emissions over 

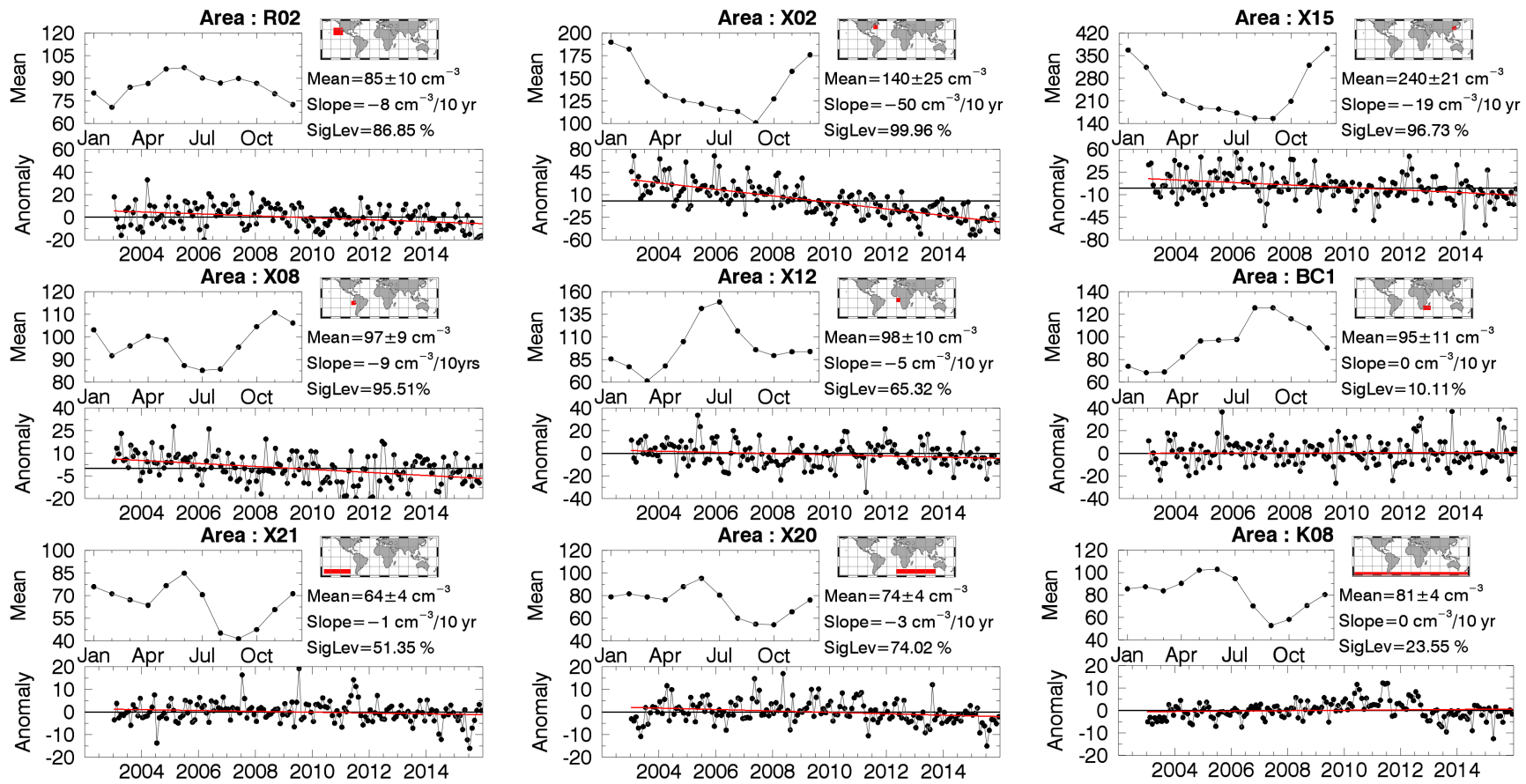

Figure 11. Mean CDNC annual cycle, monthly CDNC anomalies, and statistics for selected areas as shown in Fig. 9 and summarized in Table 3. The red curve in the anomaly plots is the regression line.

the last decade or so have partly reversed the effect seen in the original study (Bennartz et al., 2011). This speculation is substantiated by other studies that report a slight decrease in Chinese $\mathrm{SO}_{2}$ emissions from its peak value in the 2004 to 2006 time range, the decrease in $\mathrm{SO}_{2}$ emissions largely caused by flue gas desulfurization technology installed in coal power plants (Lu et al., 2011). Satellite observations suggest an even larger decrease in Chinese $\mathrm{SO}_{2}$ emissions by $50 \%$ for the recent time period 2012-2015 compared to the year 2005 (Krotkov et al., 2016).

\section{Conclusions}

The climatology described in this publication provides a number of incremental improvements over earlier climatologies published by us. Importantly, by making the climatology static and providing a DOI, we hope to be able to contribute to a better traceability of results through different studies that might use this climatology. We believe this is a particularly significant issue, as design choices in the generation of the climatology, such as data screening, can have a major influence on scientific results. To this extent we have aimed at clarifying as accurately as possible the screening choices as well as any other decisions that went into the generation of this climatology. For example, we decided to screen out any observation where the three MODIS-derived effective radii are inconsistent with the underlying assumption of the ISBLC. While this additional screening reduces data cover- age, it at least partly guards against the misinterpretation of three-dimensional radiative transfer effects in broken clouds as variability in CDNC. We further show that neglecting this screening not only leads to moderate differences in the annually averaged CDNC, but also to sometimes large shifts in phase and amplitude of the annual cycle of CDNC in various regions. Potentially adverse effects of this screening could occur in situations where the three effective radii are very close to each other, as might be the case for thin stratocumulus clouds. In such cases random noise in the observations might remove valid observations and potentially bias CDNC slightly low as preferably higher effective radii at $3.7 \mu \mathrm{m}$ would be selected. This hypothesis would be consistent with our finding comparing to the PZ11 cases. However, we believe this issue to be secondary compared to the large number of situations where the radiation field is affected by either broken clouds or precipitation, and the three effective radii clearly indicate that key assumptions in the CDNC retrieval are violated. Further retrieval issues might arise at high solar zenith angles and/or near the ice edge. At high solar zenith angles, earlier work by Grosvenor and Wood (2014) showed the effective radius at $3.7 \mu \mathrm{m}$ to be more strongly biased, potentially leading to retrieval issues. Further, cloud mask classification errors near the ice edge might lead to increased noise and artefacts in those regions.

We found some remaining retrieval artefacts in the MODIS-retrieved effective radius and optical depth that propagate through into artefacts of the CDNC climatology as well. These artefacts manifest themselves in a strong de- 
pendency of retrieved effective radius on scattering angle and could potentially be related to the treatment of first-order scattering in the MODIS Level-2 retrievals of effective radius and optical depth. Our assessment of those effects on the climatology shows however that effects clearly visible in the Level-2 data are averaged out to some degree in the aggregated climatology. We therefore did not in the final climatology include any additional screening for those effects. However, we feel that it might be beneficial in future work to recreate retrievals working directly on the Level-1 reflectances that address some of the issues we have identified. Such retrievals could be specific to stratiform boundary layer clouds and might include more appropriate assumptions for example about the width of the droplet spectrum and the stratification of the cloud as well as a finer retrieval grid or a direct calculation of the first one or two orders of scattering that corresponds to the actual observation geometry for each pixel. However, other error sources, for example related to observation geometry or broken clouds, cannot be resolved directly by retrievals of CDNC from Level 1 . Another important issue not addressed here is the consistency between Terra-MODIS and Aqua-MODIS as well as transfer of the methods derived here to geostationary satellites, in particular the recently launched GOES-16 and Himawari satellites that both provide the necessary channel settings to derive three effective radii and in addition allow one to capture the diurnal cycle of clouds with very high resolution.

Beyond these natural extensions of the current work, it will be important to devise new strategies to better derive CDNC from satellites using different types of satellite observations. Various approaches have been proposed and partially tested by other authors as outlined in the introduction. Only innovative approaches and new observational strategies will allow overcoming of some of the more difficult issues that affect CDNC observations. Examples of such issues include overlying aerosol layers as well as the effects of entrainment on the vertical profile of clouds, where assumptions made in the simple ISBLC could be replaced either by direct observations or by better assumptions that would make CDNC estimates more robust. Another important aspect is the need for more airborne in situ observations of CDNC, collocated with satellite observations, also in regions outside of the traditional stratocumulus areas. While satellite observations and modelling studies based on high-resolution numerical models can help develop and improve CDNC estimates, only in situ observations can be regarded as independent validation.

Data availability. The climatology is available in Network Common Data Format (netCDF) and adheres to the Climate and Forecast (CF) convention. The climatology is available via a digital object identifier (Bennartz and Rausch, 2016; https://doi.org/10.15695/vudata.ees.1).
Competing interests. The authors declare that they have no conflict of interest.

Acknowledgements. The authors are indebted to Rob Wood and Daniel Grosvenor for identifying and iteratively helping fix an error in the formulation of the condensation rate in Bennartz (2007). The authors are indebted to two anonymous reviewers for their thorough and constructive reviews. The authors would further like to thank Veronica Ikeshoji-Orlati for her help with publishing the dataset via the Vanderbilt Library.

Edited by: Philip Stier

Reviewed by: two anonymous referees

\section{References}

Ban-Weiss, G. A., Jin, L., Bauer, S. E., Bennartz, R., Liu, X. H., Zhang, K., Ming, Y., Guo, H., and Jiang, J. H.: Evaluating clouds, aerosols, and their interactions in three global climate models using satellite simulators and observations, J. Geophys. Res.-Atmos., 119, 10876-10901, https://doi.org/10.1002/2014jd021722, 2014.

Bennartz, R.: Global assessment of marine boundary layer cloud droplet number concentration from satellite, J. Geophys. Res., 112, D02201, https://doi.org/10.1029/2006jd007547, 2007.

Bennartz, R. and Rausch, J.: Cloud Droplet Number Concentration Climatology, https://doi.org/10.15695/vudata.ees.1, 2016.

Bennartz, R., Fan, J. W., Rausch, J., Leung, L. R., and Heidinger, A. K.: Pollution from China increases cloud droplet number, suppresses rain over the East China Sea, Geophys. Res. Lett., 38, L09704, https://doi.org/10.1029/2011g1047235, 2011.

Boers, R., Acarreta, J. R., and Gras, J. L.: Satellite monitoring of the first indirect aerosol effect: Retrieval of the droplet concentration of water clouds, J. Geophys. Res., 111, D22208, https://doi.org/10.1029/2005jd006838, 2006.

Bony, S., and Dufresne, J.-L.: Marine boundary layer clouds at the heart of tropical cloud feedback uncertainties in climate models, Geophys. Res. Lett., 32, L20806, https://doi.org/10.1029/2005g1023851, 2005.

Brenguier, J. L., Pawlowska, H., Schuller, L., Preusker, R., Fischer, J., and Fouquart, Y.: Radiative properties of boundary layer clouds: Droplet effective radius versus number concentration, J. Atmos. Sci., 57, 803-821, https://doi.org/10.1175/15200469(2000)057<0803:rpoblc>2.0.co;2, 2000.

Brenguier, J.-L., Burnet, F., and Geoffroy, O.: Cloud optical thickness and liquid water path - does the $k$ coefficient vary with droplet concentration?, Atmos. Chem. Phys., 11, 9771-9786, https://doi.org/10.5194/acp-11-9771-2011, 2011.

Burnet, F. and Brenguier, J.-L.: Observational Study of the Entrainment-Mixing Process in Warm Convective Clouds, J. Atmos. Sci., 64, 1995-2011, https://doi.org/10.1175/jas3928.1, 2007.

Evans, K. F.: The spherical harmonics discrete ordinate method for three-dimensional atmospheric radiative transfer, $J$. Atmos. Sci., 55, 429-446, https://doi.org/10.1175/15200469(1998)055<0429:tshdom>2.0.co;2, 1998. 
George, R. C. and Wood, R.: Subseasonal variability of low cloud radiative properties over the southeast Pacific Ocean, Atmos. Chem. Phys., 10, 4047-4063, https://doi.org/10.5194/acp-104047-2010, 2010.

Grosvenor, D. P. and Wood, R.: The effect of solar zenith angle on MODIS cloud optical and microphysical retrievals within marine liquid water clouds, Atmos. Chem. Phys., 14, 7291-7321, https://doi.org/10.5194/acp-14-7291-2014, 2014.

Han, Q. Y., Rossow, W. B., Chou, J., and Welch, R. M.: Global survey of the relationships of cloud albedo and liquid water path with droplet size using ISCCP, J. Climate, 11, 1516-1528, https://doi.org/10.1175/15200442(1998)011<1516:gsotro>2.0.co;2, 1998.

Hayes, C. R., Coakley, J. A., and Tahnk, W. R.: Relationships among properties of marine stratocumulus derived from collocated CALIPSO and MODIS observations, J. Geophys. Res., 115, D00h17, https://doi.org/10.1029/2009jd012046, 2010.

Haywood, J. M., Osborne, S. R., Francis, P. N., Keil, A., Formenti, P., Andreae, M. O., and Kaye, P. H.: The mean physical and optical properties of regional haze dominated by biomass burning aerosol measured from the C-130 aircraft during SAFARI 2000, J. Geophys. Res.-Atmos., 108, 8473-8473, 2003.

Haywood, J. M., Osborne, S. R., and Abel, S. J.: The effect of overlying absorbing aerosol layers on remote sensing retrievals of cloud effective radius and cloud optical depth, Q. J. Roy. Meteorol. Soc., 130, 779-800, 2004.

He, J., Zhang, Y., Glotfelty, T., He, R. Y., Bennartz, R., Rausch, J., and Sartelet, K.: Decadal simulation and comprehensive evaluation of CESM/CAM5.1 with advanced chemistry, aerosol microphysics, and aerosol-cloud interactions, J. Adv. Model. Earth Syst., 7, 110-141, https://doi.org/10.1002/2014ms000360, 2015.

Hess, M., Koepke, P., and Schult, I.: Optical Properties of Aerosols and Clouds: The Software Package OPAC, B. Am. Meteorol. Soc., 79, 831-844, 1998.

Hoose, C., Lohmann, U., Bennartz, R., Croft, B., and Lesins, G.: Global simulations of aerosol processing in clouds, Atmos. Chem. Phys., 8, 6939-6963, https://doi.org/10.5194/acp-8-69392008, 2008.

Hoose, C., Kristjansson, J. E., Iversen, T., Kirkevag, A., Seland, O., and Gettelman, A.: Constraining cloud droplet number concentration in GCMs suppresses the aerosol indirect effect, Geophys. Res. Lett., 36, L12807, https://doi.org/10.1029/2009g1038568, 2009.

Horvath, A. and Gentemann, C.: Cloud-fraction-dependent bias in satellite liquid water path retrievals of shallow, nonprecipitating marine clouds, Geophys. Res. Lett., 34, L22806, https://doi.org/10.1029/2007gl030625, 2007.

Horvath, A., Seethala, C., and Deneke, H.: View angle dependence of MODIS liquid water path retrievals in warm oceanic clouds, J. Geophys. Res.-Atmos., 119, 8304-8328, https://doi.org/10.1002/2013jd021355, 2014.

Hubanks, P. A., Platnick, S., King, M. D., and Ridgway, B.: MODIS Atmosphere L3 Gridded Product Algorithm Theoretical Basis Document (ATBD) \& Users Guide, Collection 006, Version 4.2., NASA-GSFC, 122, available at: https://modis-images. gsfc.nasa.gov/_docs/L3_ATBD_C6.pdf (last access: 21 August 2017), 2016.

Klein, S. A. and Hartmann, D. L.: The Seasonal Cycle of Low Stratiform Clouds, J. Climate, 6, 1587-1606, 1993.
Krotkov, N. A., McLinden, C. A., Li, C., Lamsal, L. N., Celarier, E. A., Marchenko, S. V., Swartz, W. H., Bucsela, E. J., Joiner, J., Duncan, B. N., Boersma, K. F., Veefkind, J. P., Levelt, P. F., Fioletov, V. E., Dickerson, R. R., He, H., Lu, Z., and Streets, D. G.: Aura OMI observations of regional $\mathrm{SO}_{2}$ and $\mathrm{NO}_{2}$ pollution changes from 2005 to 2015, Atmos. Chem. Phys., 16, 46054629, https://doi.org/10.5194/acp-16-4605-2016, 2016.

Le Page, Y., Oom, D., Silva, J. M. N., Jönsson, P., and Pereira, J. M. C.: Seasonality of vegetation fires as modified by human action: observing the deviation from eco-climatic fire regimes, Global Ecol. Biogeogr., 19, 575-588, https://doi.org/10.1111/j.14668238.2010.00525.x, 2010.

Lu, Z., Zhang, Q., and Streets, D. G.: Sulfur dioxide and primary carbonaceous aerosol emissions in China and India, 1996-2010, Atmos. Chem. Phys., 11, 9839-9864, https://doi.org/10.5194/acp-11-9839-2011, 2011.

Maddux, B. C., Ackerman, S. A., and Platnick, S.: Viewing Geometry Dependencies in MODIS Cloud Products, J. Atmos. Ocean. Tech., 27, 1519-1528, https://doi.org/10.1175/2010jtecha1432.1, 2010.

Makkonen, R., Asmi, A., Korhonen, H., Kokkola, H., Järvenoja, S., Räisänen, P., Lehtinen, K. E. J., Laaksonen, A., Kerminen, V.M., Järvinen, H., Lohmann, U., Bennartz, R., Feichter, J., and Kulmala, M.: Sensitivity of aerosol concentrations and cloud properties to nucleation and secondary organic distribution in ECHAM5-HAM global circulation model, Atmos. Chem. Phys., 9, 1747-1766, https://doi.org/10.5194/acp-9-1747-2009, 2009.

Martin, G. M., Johnson, D. W., and Spice, A.: The measurement and parameterization of effective radius of droplets in warm stratocumulus clouds, J. Atmos. Sci., 51, 1823-1842, https://doi.org/10.1175/15200469(1994)051<1823:tmapoe>2.0.co;2, 1994.

Merk, D., Deneke, H., Pospichal, B., and Seifert, P.: Investigation of the adiabatic assumption for estimating cloud micro- and macrophysical properties from satellite and ground observations, Atmos. Chem. Phys., 16, 933-952, https://doi.org/10.5194/acp-16933-2016, 2016.

Nakajima, T. and King, M. D.: Determination of the opticalthickness and effective particle radius of clouds from reflected solar-radiation measurements. 1. Theory, J. Atmos. Sci., 47, 1878-1893, https://doi.org/10.1175/15200469(1990)047<1878:dotota>2.0.co;2, 1990.

Nakajima, T. Y., Suzuki, K., and Stephens, G. L.: Droplet Growth in Warm Water Clouds Observed by the A-Train. Part I: Sensitivity Analysis of the MODIS-Derived Cloud Droplet Sizes, J. Atmos. Sci., 67, 1884-1896, https://doi.org/10.1175/2009jas3280.1, 2010.

Painemal, D. and Zuidema, P.: Microphysical variability in southeast Pacific Stratocumulus clouds: synoptic conditions and radiative response, Atmos. Chem. Phys., 10, 6255-6269, https://doi.org/10.5194/acp-10-6255-2010, 2010.

Painemal, D. and Zuidema, P.: Assessment of MODIS cloud effective radius and optical thickness retrievals over the Southeast Pacific with VOCALS-REx in situ measurements, J. Geophys. Res.-Atmos., 116, D24206, https://doi.org/10.1029/2011jd016155, 2011.

Painemal, D., Kato, S., and Minnis, P.: Boundary layer regulation in the southeast Atlantic cloud microphysics during the biomass burning season as seen by the A-train satel- 
lite constellation, J. Geophys. Res.-Atmos., 119, 11288-11302, https://doi.org/10.1002/2014jd022182, 2014.

Platnick, S.: Vertical photon transport in cloud remote sensing problems, J. Geophys. Res.-Atmos., 105, 22919-22935, https://doi.org/10.1029/2000jd900333, 2000.

Platnick, S., King, M. D., Meyer, K. G., Wind, G., Amarasinghe, N., Marchant, B., Arnold, G. T., Zhang, Z. B., Hubanks, P. A., Ridgway, B., and Riedi, J.: MODIS Cloud Optical Properties: User Guide for the Collection 6 Level-2 MOD06/MYD06 Product and Associated Level-3 Datasets, Version 1.0, October 2015, available at: http://modis-atmos.gsfc.nasa.gov/_docs/ C6MOD06OPUserGuide.pdf (last access: 16 August 2017), 2015.

Platnick, S., Meyer, K. G., King, M. D., Wind, G., Amarasinghe, N., Marchant, B., Arnold, G. T., Zhang, Z. B., Hubanks, P. A., Holz, R. E., Yang, P., Ridgway, W. L., and Riedi, J.: The MODIS Cloud Optical and Microphysical Products: Collection 6 Updates and Examples From Terra and Aqua, IEEE T. Geosci. Remote, 55, 502-525, https://doi.org/10.1109/tgrs.2016.2610522, 2017.

Quaas, J., Boucher, O., and Lohmann, U.: Constraining the total aerosol indirect effect in the LMDZ and ECHAM4 GCMs using MODIS satellite data, Atmos. Chem. Phys., 6, 947-955, https://doi.org/10.5194/acp-6-947-2006, 2006.

Rausch, J., Heidinger, A., and Bennartz, R.: Regional assessment of microphysical properties of marine boundary layer cloud using the PATMOS-x dataset, J. Geophys. Res.-Atmos., 115, D23212, https://doi.org/10.1029/2010jd014468, 2010.

Rausch, J., Meyer, K., Bennartz, R., and Platnick, S.: Differences in liquid cloud droplet effective radius and number concentration estimates between MODIS collections 5.1 and 6 over global oceans, Atmos. Meas. Tech., 10, 2105-2116, https://doi.org/10.5194/amt-10-2105-2017, 2017.

Roberts, G., Wooster, M. J., and Lagoudakis, E.: Annual and diurnal african biomass burning temporal dynamics, Biogeosciences, 6 , 849-866, https://doi.org/10.5194/bg-6-849-2009, 2009.

Rosenfeld, D., Williams, E., Andreae, M. O., Freud, E., Pöschl, U., and Rennó, N. O.: The scientific basis for a satellite mission to retrieve $\mathrm{CCN}$ concentrations and their impacts on convective clouds, Atmos. Meas. Tech., 5, 2039-2055, https://doi.org/10.5194/amt-5-2039-2012, 2012.

Schuller, L., Brenguier, J. L., and Pawlowska, H.: Retrieval of microphysical, geometrical, and radiative properties of marine stratocumulus from remote sensing, J. Geophys. Res.-Atmos., 108, 8631, https://doi.org/10.1029/2002jd002680, 2003.

Schuller, L., Bennartz, R., Fischer, J., and Brenguier, J. L.: An algorithm for the retrieval of droplet number concentration and geometrical thickness of stratiform marine boundary layer clouds applied to MODIS radiometric observations, J. Appl. Meteorol., 44, 28-38, https://doi.org/10.1175/jam-2185.1, 2005.

Sinha, P., Hobbs, P. V., Yokelson, R. J., Blake, D. R., Gao, S., and Kirchstetter, T. W.: Distributions of trace gases and aerosols during the dry biomass burning season in southern Africa, J. Geophys. Res.-Atmos., 108, 4536, https://doi.org/10.1029/2003jd003691, 2003.

Stocker, T. F., Qin, D., Plattner, G.-K., Tignor, M., Allen, S. K., Boschung, J., Nauels, A., Xia, Y., Bex, V., and Midgley, P. M.: Climate change 2013: the physical science basis: Working Group I contribution to the fifth assessment report of the Inter- governmental Panel on Climate Change, Cambridge University Press, New York, NY, USA, 1535 pp., 2013.

Storelvmo, T., Lohmann, U., and Bennartz, R.: What governs the spread in shortwave forcings in the transient IPCC AR4 models?, Geophys. Res. Lett., 36, L01806, https://doi.org/10.1029/2008g1036069, 2009.

Suzuki, K., Stephens, G. L., van den Heever, S. C., and Nakajima, T. Y.: Diagnosis of the Warm Rain Process in CloudResolving Models Using Joint CloudSat and MODIS Observations, J. Atmos. Sci., 68, 2655-2670, https://doi.org/10.1175/jasd-10-05026.1, 2011.

Twomey, S.: The Influence of Pollution on the Shortwave Albedo of Clouds, J. Atmos. Sci., 34, 1149-1152, 1974.

Wang, K., Yahya, K., Zhang, Y., Hogrefe, C., Pouliot, G., Knote, C., Hodzic, A., Jose, R. S., Perez, J. L., Jimenez-Guerrero, P., Baro, R., Makar, P., and Bennartz, R.: A multi-model assessment for the 2006 and 2010 simulations under the Air Quality Model Evaluation International Initiative (AQMEII) Phase 2 over North America: Part II. Evaluation of column variable predictions using satellite data, Atmos. Environ., 115, 587-603, https://doi.org/10.1016/j.atmosenv.2014.07.044, 2015.

Wilcox, E. M.: Direct and semi-direct radiative forcing of smoke aerosols over clouds, Atmos. Chem. Phys., 12, 139-149, https://doi.org/10.5194/acp-12-139-2012, 2012.

Wilcox, E. M., Harshvardhan, and Platnick, S.: Estimate of the impact of absorbing aerosol over cloud on the MODIS retrievals of cloud optical thickness and effective radius using two independent retrievals of liquid water path, J. Geophys. Res.-Atmos., 114, D05210, https://doi.org/10.1029/2008jd010589, 2009.

Wood, R.: Drizzle in stratiform boundary layer clouds. Part 1: Vertical and horizontal structure, J. Atmos. Sci., 62, 3011-3033, https://doi.org/10.1175/jas3529.1, 2005.

Wood, R.: Stratocumulus Clouds, Mon. Weather Rev., 140, 2373 2423, https://doi.org/10.1175/mwr-d-11-00121.1, 2012.

Wood, R., Mechoso, C. R., Bretherton, C. S., Weller, R. A., Huebert, B., Straneo, F., Albrecht, B. A., Coe, H., Allen, G., Vaughan, G., Daum, P., Fairall, C., Chand, D., Gallardo Klenner, L., Garreaud, R., Grados, C., Covert, D. S., Bates, T. S., Krejci, R., Russell, L. M., de Szoeke, S., Brewer, A., Yuter, S. E., Springston, S. R., Chaigneau, A., Toniazzo, T., Minnis, P., Palikonda, R., Abel, S. J., Brown, W. O. J., Williams, S., Fochesatto, J., Brioude, J., and Bower, K. N.: The VAMOS Ocean-Cloud-AtmosphereLand Study Regional Experiment (VOCALS-REx): goals, platforms, and field operations, Atmos. Chem. Phys., 11, 627-654, https://doi.org/10.5194/acp-11-627-2011, 2011.

Wood, R., Leon, D., Lebsock, M., Snider, J., and Clarke, A. D.: Precipitation driving of droplet concentration variability in marine low clouds, J. Geophys. Res.-Atmos., 117, D19210, https://doi.org/10.1029/2012jd018305, 2012.

Zeng, S., Riedi, J., Trepte, C. R., Winker, D. M., and Hu, Y.-X.: Study of global cloud droplet number concentration with A-Train satellites, Atmos. Chem. Phys., 14, 7125-7134, https://doi.org/10.5194/acp-14-7125-2014, 2014.

Zhang, Y., Karamchandani, P., Glotfelty, T., Streets, D. G., Grell, G., Nenes, A., Yu, F. Q., and Bennartz, R.: Development and initial application of the global-throughurban weather research and forecasting model with chemistry (GU-WRF/Chem), J. Geophys. Res.-Atmos., 117, D20206, https://doi.org/10.1029/2012jd017966, 2012. 
Zhang, Z. and Platnick, S.: An assessment of differences between cloud effective particle radius retrievals for marine water clouds from three MODIS spectral bands, J. Geophys. Res., 116, D20215, https://doi.org/10.1029/2011jd016216, 2011.

Zhang, Z., Ackerman, A. S., Feingold, G., Platnick, S., Pincus, R., and Xue, H.: Effects of cloud horizontal inhomogeneity and drizzle on remote sensing of cloud droplet effective radius: Case studies based on large-eddy simulations, J. Geophys. Res.Atmos., 117, D19208, https://doi.org/10.1029/2012jd017655, 2012.
Zhang, Z., Werner, F., Cho, H. M., Wind, G., Platnick, S., Ackerman, A. S., Di Girolamo, L., Marshak, A., and Meyer, K.: A framework based on 2-D Taylor expansion for quantifying the impacts of subpixel reflectance variance and covariance on cloud optical thickness and effective radius retrievals based on the bispectral method, J. Geophys. Res.-Atmos., 121, 7007-7025, https://doi.org/10.1002/2016jd024837, 2016.

Zhao, X. P., Heidinger, A. K., and Walther, A.: Climatology Analysis of Aerosol Effect on Marine Water Cloud from LongTerm Satellite Climate Data Records, Remote Sensing, 8, 300, https://doi.org/10.3390/rs8040300, 2016. 